\title{
An Augmented Reality Learning Toolkit for Fostering Spatial Ability in Mathematics Lesson: Design and Development
}

\author{
Bilal Ozcakir ${ }^{1 *}$, Erdinc Cakiroglu ${ }^{2}$ \\ ${ }^{1}$ Alanya Alaaddin Keykubat University, Faculty of Education, TURKEY \\ ${ }^{2}$ Middle East Technical University, Faculty of Education, TURKEY \\ *Corresponding author: bilalozcakir@gmail.com
}

Received: 26 Jun. 2021 • Accepted: 24 Aug. 2021

Citation: Ozcakir, B., \& Cakiroglu, E. (2021). An Augmented Reality Learning Toolkit for Fostering Spatial Ability in Mathematics Lesson: Design and Development. European Journal of Science and Mathematics Education, 9(4), 145-167. https://doi.org/10.30935/scimath/11204

\begin{abstract}
:
Previous research claimed that integration of augmented reality on educational settings helps to improve academic achievement of students in collaborative learning environments, as well as to improve their retention and ability to translate this within other environments. Since augmented reality is still considered relatively novel technology in educational fields, there is an inherent need for research-based guides to design effective and feasible augmented reality tools for school-based learning. The main aim of this study was therefore to design and develop an augmented reality learning toolkit to foster spatial ability in middle school students using mobile devices. The study was conducted in two parts, as preliminary research and a prototyping phase. The findings guided the characteristics for designing an augmented reality learning toolkit with a set of spatial tasks aimed at middle school students. In light of the results, it can be inferred that the students were able to use this designed toolkit to perform their spatial ability through given spatial tasks since the students encountered no technical difficulties with the final toolkit prototype, and that they were able to use the toolkit assuredly. In conclusion, the study showed that augmented reality seemed helpful in enhancing the usage of mobile devices, not just for the reading of books, communication or playing games, but also as a support mechanism for the learning of mathematics. Thus, the augmented reality toolkit developed in this study presents a new way for students and/or teachers to use mobile devices in the learning and teaching of mathematics.

Keywords: augmented reality, spatial ability, mathematics education, middle school mathematics, educational design research
\end{abstract}

\section{INTRODUCTION}

Today's technology provides opportunities for learners to access and interact through simulated learning experiences. Since much of the youth and adult population have access to handheld mobile devices like smartphones and tablet computers, this accessibility of technology brings about opportunities in almost any physical place and at any time (Maiti \& Tripathy, 2012). However, these learning experiences remain at a virtual level and rarely enter the usual or conventional learning environment (Frank \& Kapila, 2017). Augmented Reality (AR) blurs the boundary between the virtual experience and reality by enhancing the realism of such experiences. Conventional environments for learning geometry through viewing two-dimensional representations of three-dimensional objects through textbooks or on the whiteboard creates a kind of "cognitive-filter" to realizing these figures as representative of three-dimensional objects (Alcañiz et al., 2010). Furthermore, since manipulative interaction with virtual objects on a computer screen is possible through the use of a mouse, keyboard or touch panel, the cognitive-filter still remains an issue whilst using computer screens and twodimensional projections (Alcañiz et al., 2010; Shelton \& Hedley, 2004). AR technology, on the other 
hand, helps us to deal with this cognitive-filter by combining the real-world environment with virtual elements.

\section{Spatial Ability and Technology}

Many different terms can be found to define and describe spatial ability in the literature. For example, spatial thinking (Yakimanskaya, 1991), spatial sense (NCTM, 1989), spatial skills (Tartre, 1990), spatial reasoning (Battista, 2007), spatial cognition (Sjölinder, 1998) are presented by researchers to define mental visualization, manipulations as well as rotations for figures and shapes. In brief, the essence of these definitions implies common ideas like ability of rotating, transforming or envisioning an object and manipulating its properties mentally. Similar to the use of multiple concepts to define spatial ability, there are several categorizations for components of spatial ability. Battista (1994) categorized spatial ability into two components as spatial orientation and spatial visualization. Similarly, Pellegrino and Kail (1982) divided spatial ability into two categories but as spatial relations and spatial visualization. Additionally, some researchers categorized spatial ability into three elements as mental rotation, spatial perception and spatial visualization (Linn \& Petersen, 1985) or as spatial visualization, spatial orientation, and spatial relations (Lohman, 1993). Although there were different categorizations for components of spatial ability, these all components could form a common sense for spatial ability. Maier (1996) claims that due to a variety of spatial-visual problems which we are faced in technological worlds, and to gain detailed knowledge of spatial abilities, there is a need for a specification into more than three elements. Therefore, Maier (1996) distinguishes five elements of spatial ability as mental rotation, spatial perceptions, spatial visualization, spatial relations and spatial orientation, so on suggests that the technological developments demand the training of these five elements. In Maier (1996) categorization of spatial ability, spatial perception is the ability to designate spatial relationships about the location of the vertical or the horizontal despite of distracting information (Maier, 1996). Spatial visualization is the skill to visualize and manipulate complex spatial information for a figure when there is a movement or displacement among components of the figure (Linn \& Petersen, 1985; Maier, 1996). Mental rotation is the skill to make a rapid and accurate rotation of two or three dimensional figures mentally (Linn \& Petersen, 1985; Maier, 1996). Spatial relations refer to the skill to understand the spatial configuration of objects or components of an object and their relations to each other (Maier, 1996). Spatial orientation is an understanding on relationships between different positions of objects, especially with respect to one's own position. As is seen from the literature review, there is no general agreement on both definitions of spatial ability and components of spatial ability. The current study focused on spatial visualization ability of students since the focus is mainly given on spatial visualization component in terms of objectives related to spatial ability in seventh grade mathematics curriculum of Turkey (MoNE, 2013). Moreover, Fennema and Sherman (1977), and van Garderen (2006) argued that spatial visualization component of spatial ability is more related to mathematics achievement.

For students, spatial ability requires them to analyze a projective representation of an object in terms of its components and recombining these components (Stiles \& Stern, 2001). Thus, improvement in spatial ability can help students overcome the unwanted effects of the aforementioned cognitive-filter. Learners can recognize and comprehend spatial problems and spatial relations between and within objects while interacting and working directly with virtual elements as in real-world settings, sometimes even more effectively (Kaufmann, 2004). Similarly, the AR interface provides very important and effective ways for learning three-dimensional geometric objects by mimicking reality via only supplementing it with virtual elements in order to overcome the cognitive-filter. By the way, real and concrete threedimensional objects such as cubes and prisms or other mathematics learning materials are powerful tools in providing appropriate learning experiences to young learners. However, within instruction on spatial ability using real objects, learners can only be provided with a limited number of threedimensional examples since these materials are generally in solid forms and not have dynamic and interchangeable features. AR interface, on the other hand, can provide learners with a variety of virtual dynamic three-dimensional structures to work with, since they can be created virtually without the barriers of physics of the real world. 
Previous research had shown that training of spatial ability could be accomplished via novel technologies like VR and AR by creating interactive three dimensional environments in mathematics lessons (Rafi et al., 2008). Moreover students comprehend mathematical concepts about two and three dimensional geometry better via AR tools in learning phase (Chen, 2019; Elsayed \& Al-Najrani, 2021; Flores-Bascunana et al., 2020). There is a limited number of systematic studies about human spatial cognition and spatial abilities, which is related to AR environments. Kaufmann and Schmalstieg (2002) developed Construct3D software in order to foster spatial abilities of learners and to maximize transfer of learning, and investigated its effects. They claimed that Construct3D improved spatial abilities and encouraged experimentation with geometric constructions. On other hand, Shelton (2003) examined how learners change the way to understand topics that involves dynamic spatial relationships while interacting with virtual objects. Findings of the study of Shelton (2003) indicated that AR can be used in learning environments to influence and supplement students' spatial understanding to envision concepts and create a more comprehensive understanding about these concepts. Similarly, Hedley (2003) found that AR interface provides advantages over desktop-based technology interface in a range of task-based activities for users, including task performance, task speed, completeness, and the level of user's spatial ability to directly manipulate three dimensional AR models. Hedley (2003) also suggested that through multisensory interaction, AR interface may spread cognitive load for users, thereby reducing cognitive inertia. Furthermore, Dünser et al. (2006) studied about trainability of spatial ability by AR application. They deduced that fostering spatial ability using AR could be possible. Moreover, Martín-Gutiérrez et al. (2010) developed AR-Dehaes book and AR-based application based on the modified model to improve spatial abilities of college students. They found that this intervention had positive impact on spatial ability of students. Elsayed and Al-Najrani (2021) signified that the AR interface, which they used in their research, enhanced ideas' discriminating and analyzing of shapes and situations from represented images, videos, and media on AR space since students could practice on virtual shapes and objects while experimenting them through interface. Thus, students had an opportunity for developing their visual thinking skills. Finally, Flores-Bascuñana et al. (2020) stated that using AR interface on mathematical learning settings could develop students' understandings about three dimensional concepts in mathematics, effectively. Therefore, AR based materials promote students' acquisition of geometric and spatial abilities in learning phase. In summary, AR interface has potentials to increase understanding about concepts, to improve students' learning in spatial structures (Dünser et al., 2006; Elsayed \& Al-Najrani, 2021; Flores-Bascuñana et al., 2020; Hedley, 2003; Kaufmann \& Schmalstieg, 2002; Martín-Gutiérrez et al., 2010; Shelton, 2003) and to increase students' motivation (Chen, 2019; Demitriadou et al., 2020; Kaufmann \& Schmalstieg, 2002; Martín-Gutiérrez et al., 2010; Shelton, 2003).

Since AR is still considered relatively novel technology in educational fields, there is an inherent need for research-based guides to design effective and feasible AR tools for school-based learning. Thus, the purpose of the current study was to make conjectures about the design principles/guidelines for an AR learning toolkit, which includes a set of spatial tasks and a mobile AR interface, and to design an AR learning toolkit to foster spatial understanding of middle school students in mathematics lessons. The collection of spatial tasks and the mobile AR interface developed compose a toolkit named as the Spatial Augmented Reality (SPATIAL-AR ${ }^{1}$ ) Toolkit throughout this research.

\section{METHOD}

This study utilized an educational design research (EDR) approach, which involves a systematic way of design, development and formative evaluation of an educational intervention or innovation (Plomp, 2013). Generally, the EDR commonly has three phases of research that are a preliminary research phase, a prototyping or development phase, and an evaluation phase (Nieveen \& Folmer, 2013). One aim of

\footnotetext{
${ }^{1}$ You can download the demo version of Spatial-AR toolkit (app for Android OS, sample tasks and qrcodes) here: http://bilalozcakir.com.tr/matar/matar_spatialar.html
} 


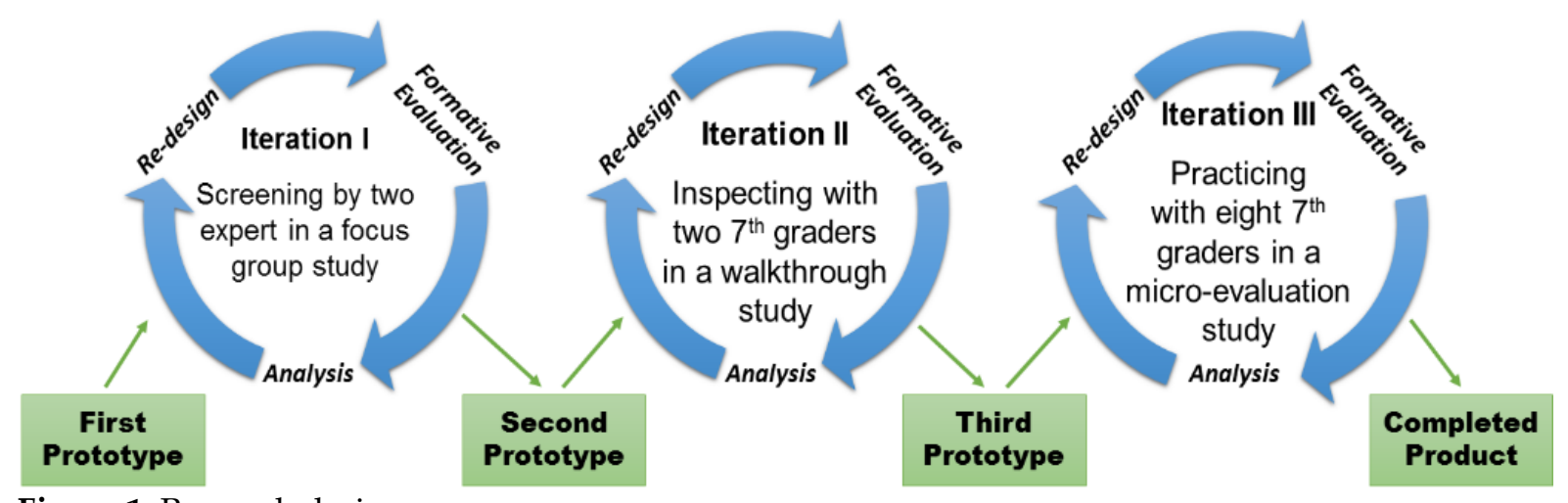

Figure 1. Research design

the current study was to contribute to the field of education with regards to the potential attributes and characteristics of an instructional intervention that makes use of AR technology. In this way, by formative evaluation of a prototypical instructional intervention through iterative cycles, the aim was to produce a knowledge-base for future and more advanced interventional designs. The current study was conducted in two parts; the first of which was a preliminary research and the second was the prototyping phase. Firstly, the preliminary research phase was about reviewing related literature to find out basic design principles to be considered while designing and developing the SPATIAL-AR toolkit. Thus, contents for spatial ability tasks, key elements for coding a mobile AR interface, and characteristics of learning environment to support AR based instruction were derived as draft design principles within the review of the literature. Secondly, the prototyping phase included three micro-cycles to redesign, evaluate and analyze the prototype (see Figure 1).

These iterations were about designing, developing and improving cycles for prototypes of the SPATIAL-AR toolkit. The prototyping phase was shaped in accordance with Nieveen and Folmer (2013) methods. Nieveen and Folmer (2013) signified some appropriate methods for determining participants in order to address cycles of iterations. These methods are described as:

- Screening: Experts checks relevancy of the design. So that the intervention can be more relevant from a subject matter perspective.

- Focus Group: A group of participants as experts carries out a prototype of a product. Hence the prototype can be more consistent with design guidelines.

- Walkthrough: A group of representatives of the target students carries out prototype in order to reveal expected practicality of the prototype within target students.

- Micro-evaluation: A small group of target students, who are sampled as high-achieving and lowachieving as well as average students, uses product outside of its intended target settings for students. Thus, its practicality and expected effectiveness could be revealed.

Throughout the manuscript, screening, focus group, walkthrough and micro-evaluation terms were used as defined above. The first iteration of this phase was planned as a mix of both screening and focus group methods and it was called as focus group study. Two experts from mathematics education participated to this focus group study. They carried out the first prototype of SPATIAL-AR toolkit and helped to improve it. In this iteration, the SPATIAL-AR toolkit was redesigned considering derived information form these experts about its irrelevant and inconsistent characteristics from subject matter perspective. The following iteration was planned as a walkthrough study. In this iteration, two seventh graders with high spatial ability were selected to improve the design from students' perspective as well as to conjecture expected practicality of the SPATIAL-AR toolkit for target students. The third and last planned iteration was designed as micro-evaluation study. For this iteration, eight seventh graders were selected from high, average and low spatial ability students in order to provide diversity in groups by and so constitute a sample which represents all levels of spatial ability. In this iteration, students were 


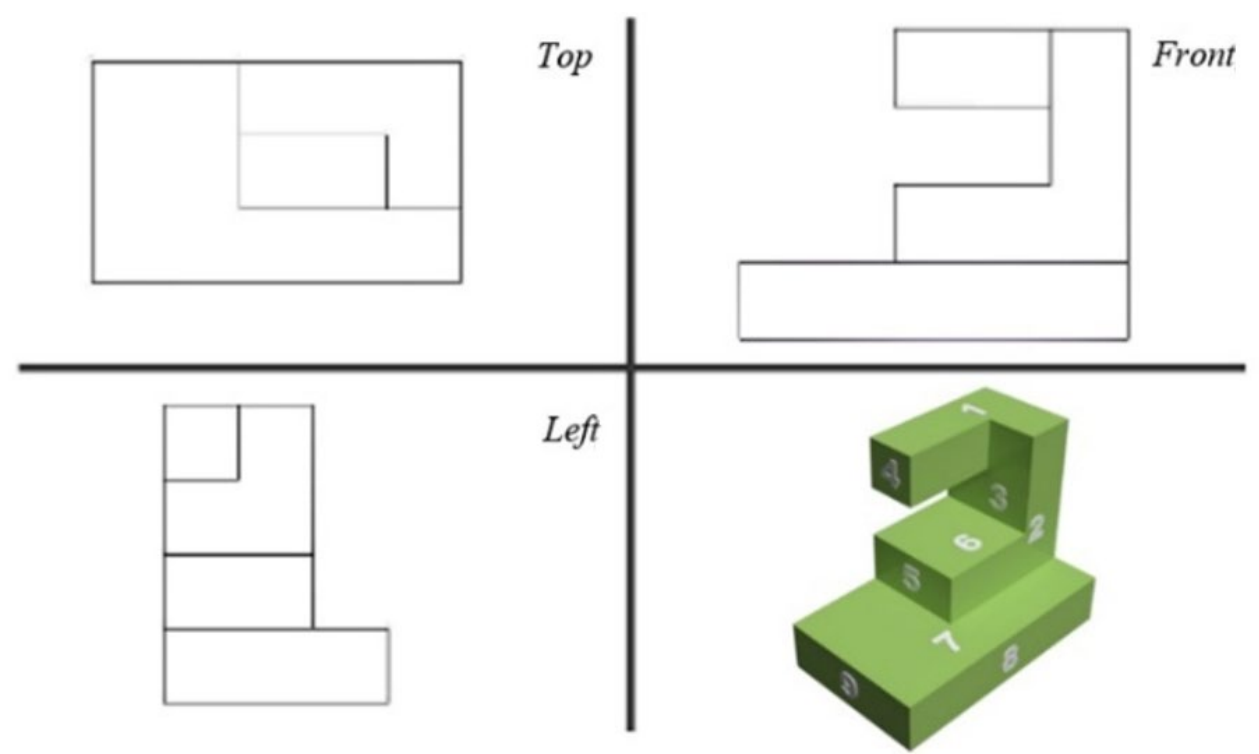

[Activity 3: Write the numbers on surfaces of the virtual object onto orthographic views.]

Figure 2. Surfaces and vertices category of GISAR

grouped in accordance with their scores in the Purdue Spatial Visualization Test (PSVT), which was developed by Guay (1977) and adapted in Turkish language by Uygan and Kurtuluş (2016). The PSVT was used as an indicator of students' spatial abilities. This time, main goal was to reveal actual practicality of the SPATIAL-AR toolkit as well as expected contributions of it to spatial ability of students and to learning environment. During and after each iteration, the prototype of SPATIAL-AR toolkit was revised and redesigned according to findings. Thereby, design principles were conjectured and reshaped at each iteration. In short, output of each iteration became input of following ones.

\section{First Phase: Preliminary Study}

In light of the related literature, some possible design guidelines were derived as initial guides for spatial contents for designing an AR interface to foster students' spatial ability. Consequently, the preliminary research phase led to guides for improving spatial ability with AR (GISAR) which specifies spatial contents for tasks, draft design principles for AR learning environment and draft key elements of a mobile AR interface. According to these design principles, a prototype SPATIAL-AR toolkit was designed and developed throughout this research.

\section{Initial Guides for Improving Spatial Ability with AR Tasks (GISAR)}

Spatial tasks in this study were formed in four categories. These categories and characteristics were defined especially for using with AR technology. First of all, a surfaces and vertices category included tasks about identifying parts of three-dimensional virtual objects. In this category, characteristics for tasks were the identification of surfaces on orthographic views, identification of surfaces on perspective views, and identification of vertices on both orthographic and perspective views (see Figure 2).

The second category was counting. In this category, spatial tasks have characteristics about having an object formed from separate and identical components which can be countable to identify components in touch with each other (see Figure 3).

Matching correct view was the third category. This category was defined with characteristics about determining correct orthographic views from organized lists as top, left and side, and disorganized lists of orthographic views (see Figure 4). 

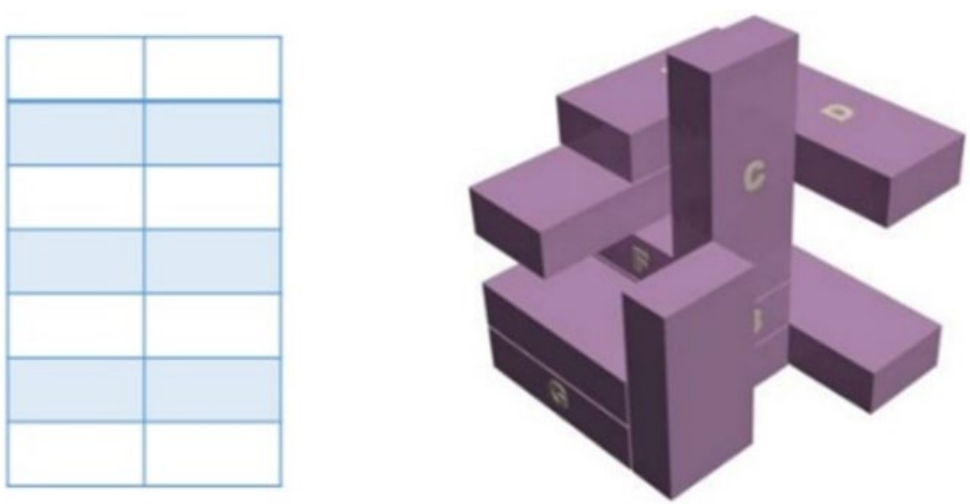

[Activity 4: .... write the number of bricks which are in touch with titled bricks.]

Figure 3. Counting category of GISAR

A

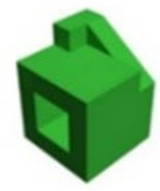

C

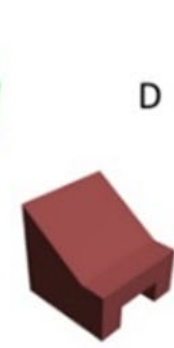

B

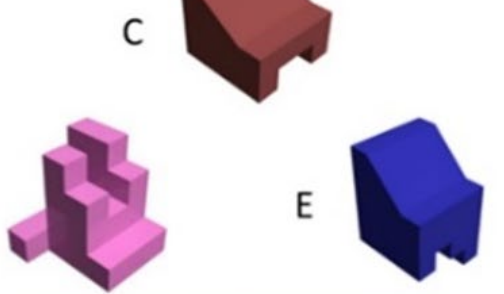

\begin{tabular}{|c|c|c|c|}
\hline & Top & Front & Left \\
\hline A & & & \\
\hline B & & & \\
\hline C & & & \\
\hline D & & & \\
\hline E & & & \\
\hline
\end{tabular}

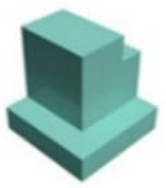

1

[Activity 1: Match side-views with objects.]

Front

2

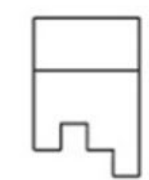

5

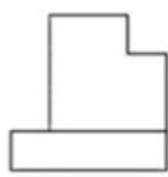

8

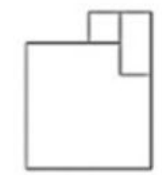

11

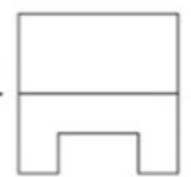

14

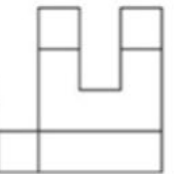

3

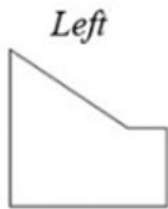

6

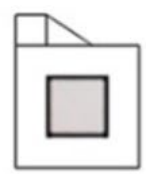

9

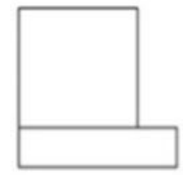

12

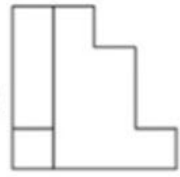

15

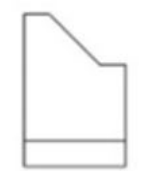

Figure 4. Matching correct views category of GISAR

The last category was the second dimension - sketches. This category was concerned with sketching different orthographic views of objects by investigating virtual three-dimensional objects. The sketching tasks involved two characteristics, which were sketching missing orthographic views and sketching all orthographic views from three directions (see Figure 5). 


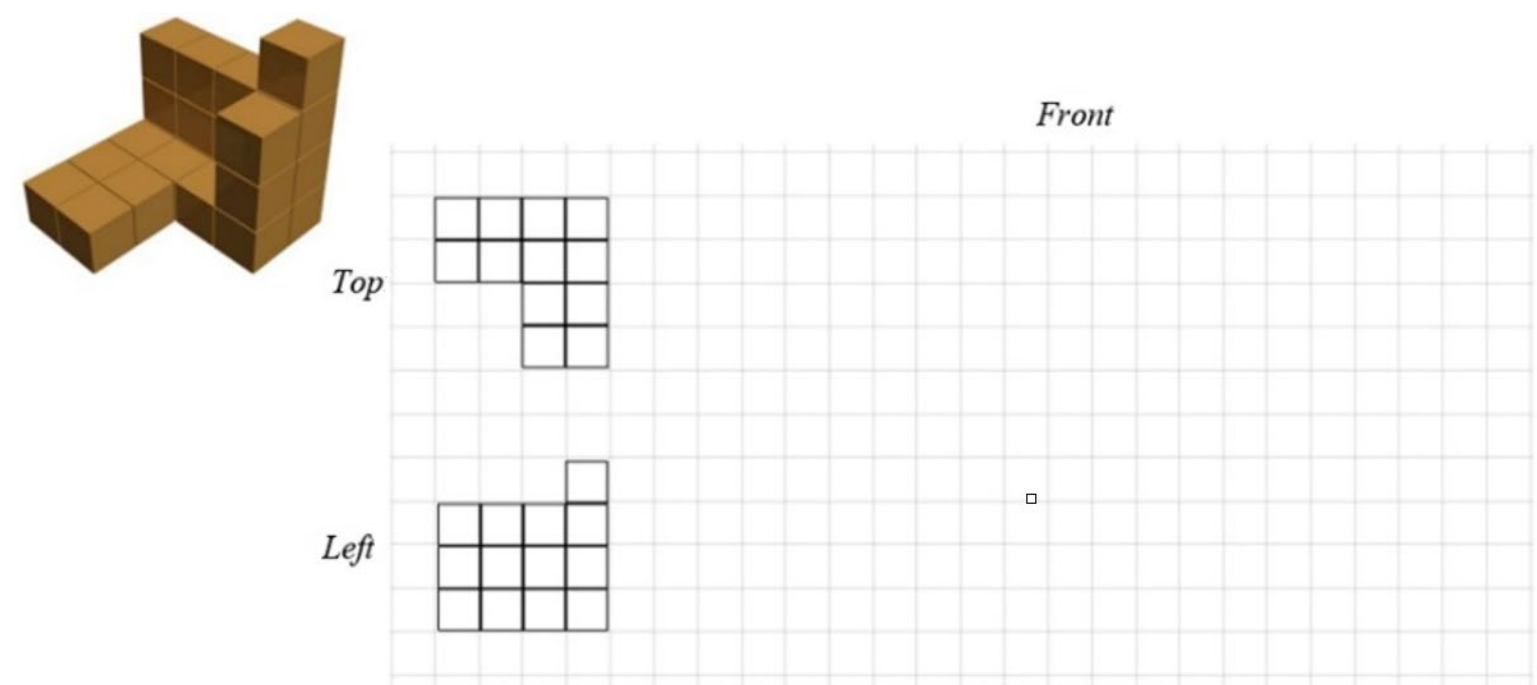

[Activity 4: Investigate virtual object via tablet or smart glasses. Sketch missing side-view of the virtual object.];

Figure 5. Sketching category of GISAR

The spatial tasks in this study were designed analyzing characteristics of spatial ability from the Turkish middle school mathematics curriculum (MoNE, 2013), and spatial ability models from other published research (Martín-Gutiérrez et al., 2010; Sack \& van Niekerk, 2009; Wiesen, 2015). These guides were shaped and reviewed throughout the phases of this research in order to combine the most suitable tasks for the improvement of students' spatial ability. Spatial tasks and virtual objects for an AR learning environment were designed in the current study in accordance with these guides.

\section{Initial Design Principles for AR Learning Environment based on the State of the Art}

Three basic initial design principles were derived from previous studies by considering common features and opportunities provided to learning environment via AR technologies. An AR learning environment for developing spatial ability should include the following:

1. Unique interactions with the opportunity for physical, natural ways of interaction with virtual objects which are as similar to real objects and include collaboration with peers as in a conventional learning environment (Billinghurst \& Kato, 2002; Smith \& MacGregor, 1992; Szalavári et al., 1998);

2. Opportunities for engaging in an active process for learning, to move freely within an environment and to control own independent viewpoints for virtual objects by eliminating students' status as passive observer (Smith \& MacGregor, 1992; Sundberg, 1996; Szalavári et al., 1998);

3. Teacher opportunities such as providing different types of task and information about learners' progress, with just-in-time feedback provided to students with regards to their progress (Wu et al., 2013).

Since these principles interrelate to both the constituent elements of spatial tasks and AR interfaces, these principles require both spatial tasks and an AR interface in order to perform to their design purposes.

\section{Initial Key Elements of a Mobile AR Interface}

The AR interface designed and developed in the current study considered a list of key elements of an AR interface with Unity 3D and Vuforia Software Development Kit. For this purpose, two basic key elements of "virtuality for objects" and "augmentation of environment," which define a coded interface as AR, were derived from the literature in terms of the key elements of an AR interface (Azuma, 1997; Kaufmann, 2004; Szalavári et al., 1998). These key elements are the common technical features of any AR application, and were therefore considered as the starting point to reveal other features of AR applications for mobile environments, which were then developed and administered throughout this 
research. According to these all draft design principles, a prototype of SPATIAL-AR toolkit was designed and developed as including a mobile AR interface and a student booklet which includes both spatial tasks and target images for virtual objects in this interface in order to serve as instructional tool for the following iterations.

\section{First Iteration of the Study}

The goal of this study was to guide and improve the design of the SPATIAL-AR toolkit from a subject matter perspective. Participants in this group study were two mathematics educators at age 31 and 33 respectively, each with a master's degree in Mathematics Education. Moreover, these participants have also teaching experiences at middle school level of mathematics at least three years. These participants were aware of AR technology, but they had not used any AR tool until this research. On the other hand, they had conducted one or two research about learning tasks with three dimensional geometry concepts. In their research, they had developed three-dimensional learning tasks with dynamic geometry software like GeoGebra 3D and Cabri 3D. Therefore, they had experiences with designing and administering learning tasks by using virtual three-dimensional objects without AR technology.

Previous studies have indicated that mathematics and spatial ability have a strong relationship (Battista, 1990; Olkun, 2003). Therefore, mathematics educators were considered to be aware of the value of spatial ability, and they could be expected to have a reasonable spatial ability level. These factors could help them know what were expected from them while they are carrying out spatial tasks in AR learning environment. In addition, these factors helped the researcher to collect efficient data so as to make proper adjustments for the SPATIAL-AR toolkit.

The focus points of this phase were the participants' works, and their feedbacks about appropriateness of the SPATIAL-AR toolkit to middle school students. The participants were provided with the first prototype of SPATIAL-AR toolkit. This prototype was designed to include 111 different virtual threedimensional objects and 73 spatial tasks as a pool for learning tasks. The participants were provided with the first prototype of the SPATIAL-AR toolkit. The participants were asked to carry out the activities and express their way of thinking with tablet computers and Smart glasses. The participants' feedback and comments, as well as data collected from other sources, were then analyzed in order to make the SPATIAL-AR toolkit more appropriate to the Turkish national middle school mathematics curriculum and to be more stable for use within an AR learning environment.

\section{Second Iteration of the Study}

The goals of the walkthrough study were to guide and improve the design of the SPATIAL-AR toolkit through 7th grade students' experiences in an AR learning environment, and to conjecture the expected practicality of the toolkit with representative target students. Two participants were chosen for this iteration, selected from 7th grade (age range: 11-12) students of a public middle school in Kırşehir, Turkey, in accordance with their spatial ability levels among 66 students in their grade. Since this iteration was still about designing, developing, and updating the second prototype of the SPATIAL-AR toolkit, only students with a reasonable spatial ability level were considered as being appropriate for this iteration.

In this iteration, the second prototype of the SPATIAL-AR toolkit, which was revised after previous iteration, was used as the learning material. This prototype toolkit included approximately 44 different virtual three-dimensional objects and the student's booklets included 36 spatial tasks and target images for these virtual objects. The participants worked together in computer laboratory of a public middle school in Kırşehir. Since this was students' first encounter with the AR technology, it was briefly explained what augmented reality technology is. After that, the participants tried to explore spatial relationships between objects and their projections by following directions in tasks. This study provided helpful data to enhance tasks in order to make them more suitable and robust for application, as well as to develop a proper and practical SPATIAL-AR toolkit for the AR learning environment. 


\section{Third Iteration of the Study}

The goal of the micro-evaluation study was to guide and improve the design of the SPATIAL-AR toolkit through 7th grade students' experiences with AR learning activities in their real learning settings. Eight participants were chosen for this iteration, selected from 7th grade (age range: 11-12) students at a public middle school in Kırşehir, Turkey, since due to technical limitation of the study and in order to supply all students a device, the participants were chosen purposefully from 26 students in terms of their spatial ability levels. There were four tablets and four smart glasses for the study. This iteration focused both designing processes of AR learning environment and possible outcomes of this environment. Since the main focus point of this paper was to explain designing processes of AR learning environment, possible outcomes of this environment have been subjected for another research.

In this iteration, the third prototype of the SPATIAL-AR toolkit, which was revised after previous iteration, was used as the learning material. This prototype toolkit included approximately 47 different virtual three-dimensional objects and the student's booklets included 33 spatial tasks and target images for these virtual objects. The participants worked together in a regular classroom.

\section{Data Analysis}

The data were collected through several different sources such as interview sessions, video recordings of the learning environment, screen captures, worksheets, audio recordings, and observation logs. Moreover, video recordings and screen video captures of devices were synchronized in order to understand the participant nonverbal interaction with virtual objects and with their peers such as pointing, gesturing, gazing or relocating. In order to proceed data analysis and to create meaningful categories from these data, the documented data, observation notes and worksheets were read several times to deduce and comprehend what happened throughout the study (Creswell \& Poth, 2016). At the meantime, synchronized video records were also watched several times in order to understand participants' ways of interactions and possible glitches about programming of AR interface. These documenting audial data, synchronizing visual data and analyzing these data were applied in MAXQDA software. After these reading and watching processes, relevant and useful data were disassembled from all the other data in order to focus important factors related with research questions and aims of the iterations. Moreover, other data sources like videos were also analyzed in order to extract visual and nonverbal units of data as well as if exist to verify and validate founded units of data from written sources with visual ones. After extracting units of data, they were roughly separated and coded in accordance with their relation. Similar or related codes were grouped together to form tentative categories. Definitions of the codes and categories were noted on their names in the MAXQDA software in order to prevent confusion through data analyses process (Creswell \& Poth, 2016). Finally, these categories were grouped and related with pre-determined themes in accordance with respect to research questions and aims of the iterations (Table 1).

The data analyses focused on three main themes, as issues regarding the AR interface, booklets, and tasks, since the study is concerned with the design, development, and improvement of the SPATIALAR toolkit. 
Table 1. Coding categories regarding to improvement of the prototype

\begin{tabular}{|c|c|c|}
\hline Themes & Categories & Criteria \\
\hline \multirow[t]{4}{*}{ AR Interface } & $\begin{array}{l}\text { Issues about recognition of qr-codes } \\
\text { Issues about projection of virtual objects }\end{array}$ & $\begin{array}{l}\text { Issues about recognition about target images or / and superimposing of } \\
\text { virtual object on these target images were considered. }\end{array}$ \\
\hline & Interacting with interface & $\begin{array}{l}\text { Interactivity opportunities or deficiencies about usage of interface were } \\
\text { considered. }\end{array}$ \\
\hline & Determining orientation for objects & Mimicking reality issues were considered. \\
\hline & Issues about pure programming & $\begin{array}{l}\text { Pure programming which can prevent stable usage of interface were } \\
\text { considered. }\end{array}$ \\
\hline \multirow[t]{2}{*}{ Booklet } & Usability of booklet in AR & $\begin{array}{l}\text { Opportunities or deficiencies for affective interactions with virtual } \\
\text { objects were considered. }\end{array}$ \\
\hline & Directions about tasks & Clarity of tasks and directions of them were considered. \\
\hline \multirow[t]{3}{*}{ Tasks } & Timing & Needed time to complete tasks were considered. \\
\hline & Appropriateness of tasks & Relevancy of tasks to curriculum were considered. \\
\hline & Adaptation of students to $\mathrm{AR}$ & Whether students get used to AR. \\
\hline
\end{tabular}
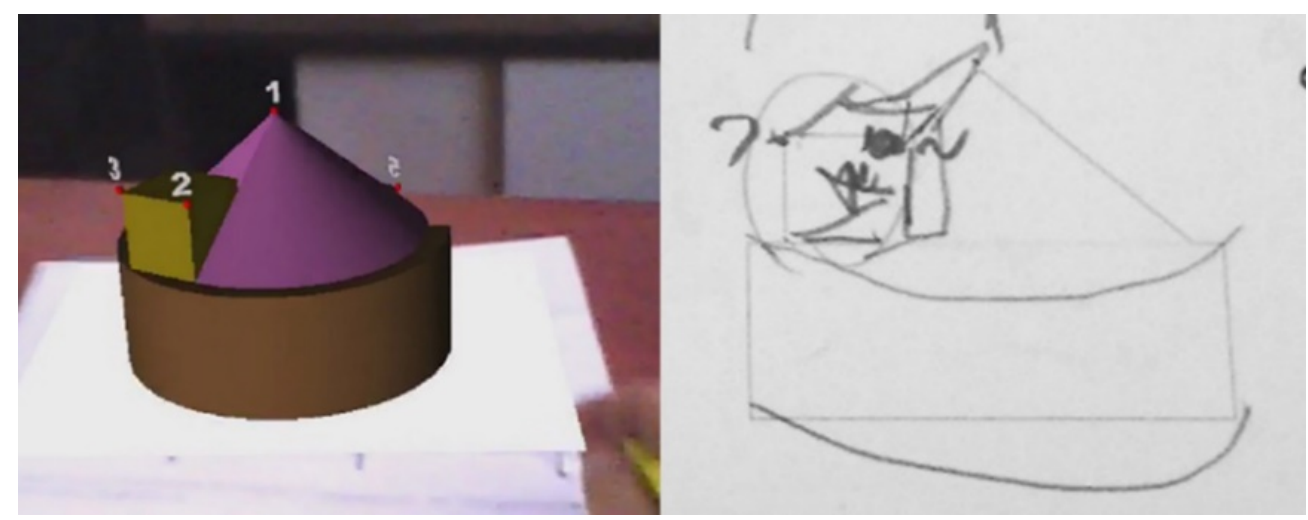

Figure 6. Screen capture of participant's point of view which caused some confusion

\section{RESULTS}

The findings provided a formative evaluation of the implementation process, which led to design principles being established in order to improve the design by explaining the constituent elements of this development process and articulated a GISAR in order to provide a way to put theory into practice. The reasons for revising the first prototype SPATIAL-AR toolkit were explained from the expert perspective with findings from the focus group study, and the second and third prototypes from the student perspective with findings from the walkthrough study.

\section{Findings About the AR Interface}

First of all, according to the findings of the focus group study, it was revealed that locating virtual objects at the base layer of virtual space, which refers to the very top of the target image in the real world, made it hard to see the exact front, left and other sides of the virtual objects. Due to this issue, one participant experienced some confusion whilst examining a virtual object with a cylindrical component in one of the tasks (see Figure 6). The orthographic view of this component of the virtual object from the exact front side should appear like a rectangle. However, he insisted that it did not look like a rectangle and stated that the front view was supposed to be changed as his drawing in shown as Figure 6 .

As can be seen on Figure 6, if the AR interface does not visualize virtual objects correctly, learners may be unable to carry out spatial tasks as expected. This issue was also found in retrospective interview 


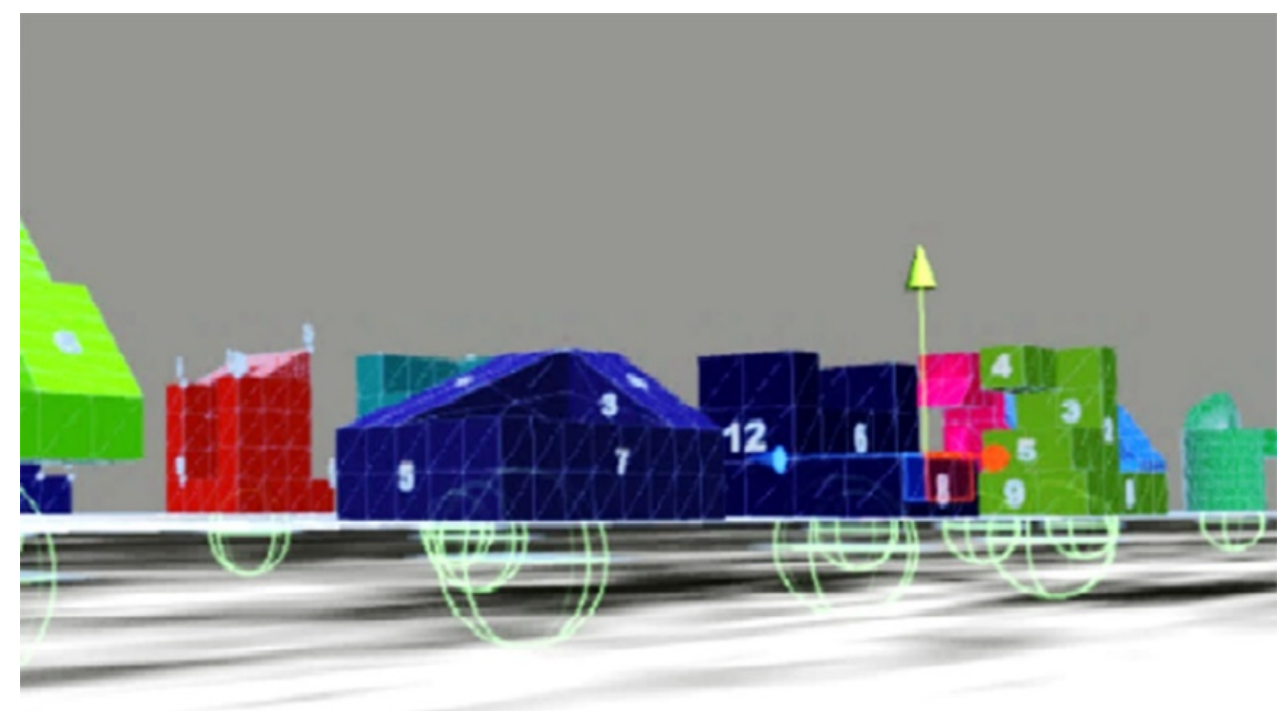

Figure 7. Revisions to vertical location

transcripts. For instance, participants stated this issue as a difficulty which they encountered during implementation as follows;
"I think software cannot detect qr-code from exact front viewpoint" [retrospective interview]

"Technical difficulty? It was hard to restore view of object if it was to disappear, and the software frequently failed to detect the view (projected virtual object) from the sides." [retrospective interview]

It was seen that the AR interface issues required visual data of target images, and therefore could not project virtual data using insufficient visual data while participants were trying to see and examine virtual objects from an exact perpendicular viewpoint. With regard to a solution to the issue, the virtual object was placed at a slightly higher point from the base plane (see Figure 7).

After the revision was applied, according to the observation notes, the same issue was not reencountered, and therefore it can be concluded that this small revision regarding the vertical location of virtual objects resolved the issue related to the projection of objects.

The other issue raised in the focus group study was with regards to a deficiency within the AR interface. This deficiency was noted in the participant feedback about the consistency of the prototype SPATIALAR toolkit with the draft design principles for AR learning environment. The tasks in the second category of the GISAR require comparisons of multiple three dimensional objects and matching these objects with their two dimensional views. Therefore, all compared virtual objects were designed to be seen and examined on a single scene. However, the participants stated some difficulties were experienced whilst comparing objects in task-based interviews; for instance, they stated;

\footnotetext{
"It would be good if we could examine these shapes (virtual objects) one-by-one. Now, I see all of them together, but it is hard to examine, how they look like from the top or side.... Because, looking both from this (virtual plane) and this (task) at the same time increases the workload." [task-based interview]
}

\footnotetext{
"You might make them (virtual objects) interactive (such that) virtual objects could make thing (expand and hide others) (when) we touch on top of them. ... examining (them) could be much easier and also students can compare all and examine one-by-one." [task-based interview]
} 


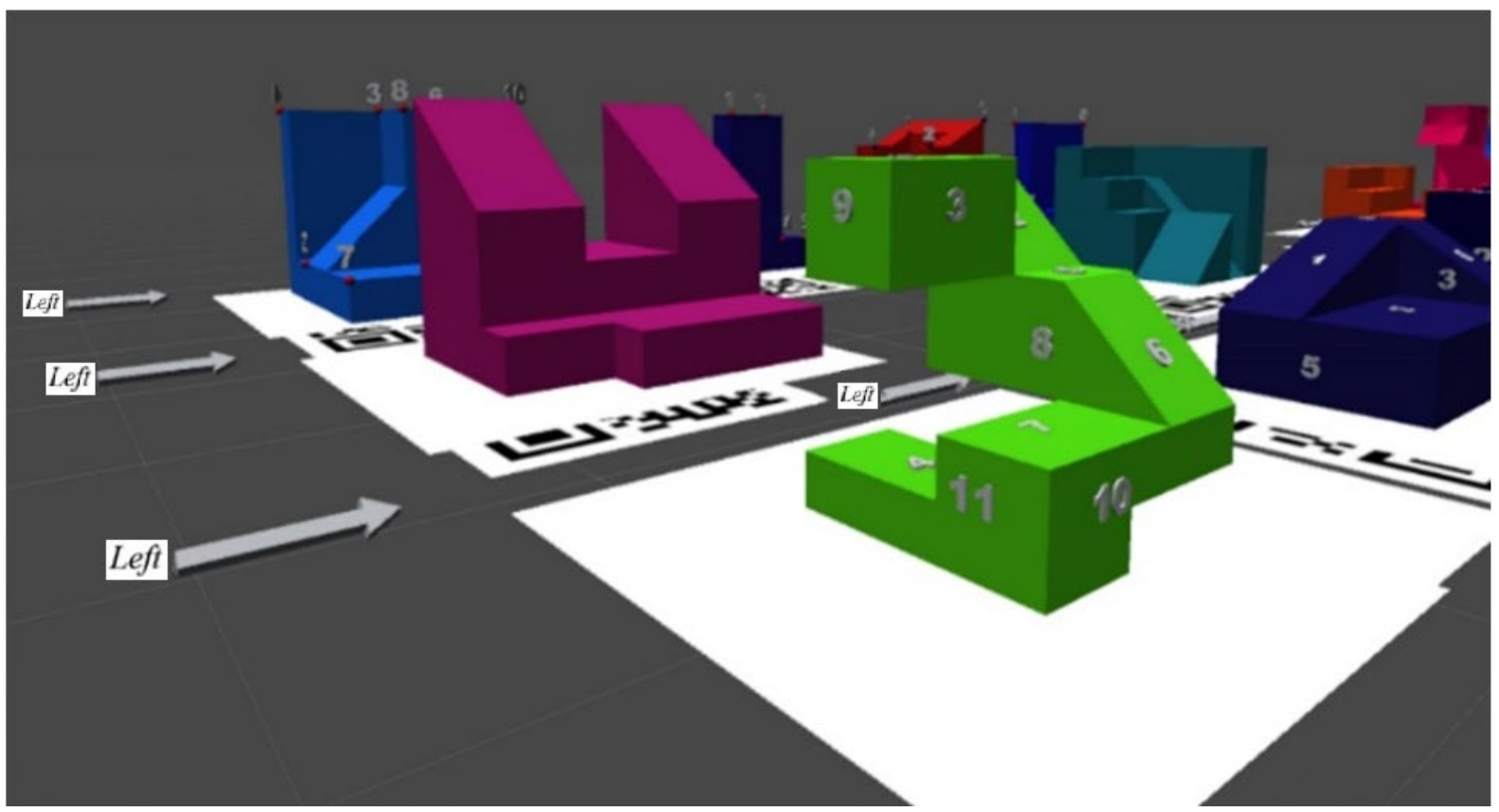

Figure 8. Modification about direction

As seen with these transcripts, if the AR interface included some kind of interactivity layers, students may have the opportunity to compare and examine virtual objects in both multiple-view and singularview. Therefore, a touch or pointer control C\# script was written and added to the AR interface in order to provide such a level of interactivity. As a result of these revisions, the AR interface was redesigned and updated in the second prototype of the SPATIAL-AR toolkit as the learning material of the walkthrough study.

The walkthrough group, at the second iteration of the research, faced a workload issue due to a technical deficiency about determining directions of virtual objects. Elif and Meva (pseudonyms assigned by the researcher) encountered the issue on the first day of the implementation of the walkthrough study. For example, while they were working on the spatial tasks, Elif asked; "How can we find the directions? For example, do we think left direction as our left?" Similarly, Meva explained her difficulty about directions in her retrospective interview session as follows;

\section{"... I had this issue, opposite side... you know, you can look from that side (she pointed to the front side) and also from the opposite side ... Point of view I mean ... For example, we don't know this side is the front, or in fact I even don't know which side is the back. Sometimes, while I am examining the views (of objects from different directions), I go wrong and then I realize that I was looking from the back direction." [retrospective interview]}

In the preliminary research and the focus group study, the researcher had not considered that the students might be confused about the directions since, as stated previously, AR is a technology which provides a unique opportunity to mimic real-world objects with virtual equivalents. Similarly, the participants of the focus group study did not report any confusion about the direction of virtual objects during the implementation. In order to address this issue, an orientation clue was added to the AR interface design, giving users a sign showing one direction. Therefore, the users would need to think about and find other directions spatially (see Figure 8).

The direction pointer was designed and located on a relative outer point so that the pointer could be seen only by looking from the front. In this way, the students should find the other directions by themselves by using the pointer as a reference. The mobile AR interface was recoded and recompiled in accordance with these modifications and implemented for use on the second day. Once implemented, the students used the modified version of the AR interface and no issue was reported or observed with 


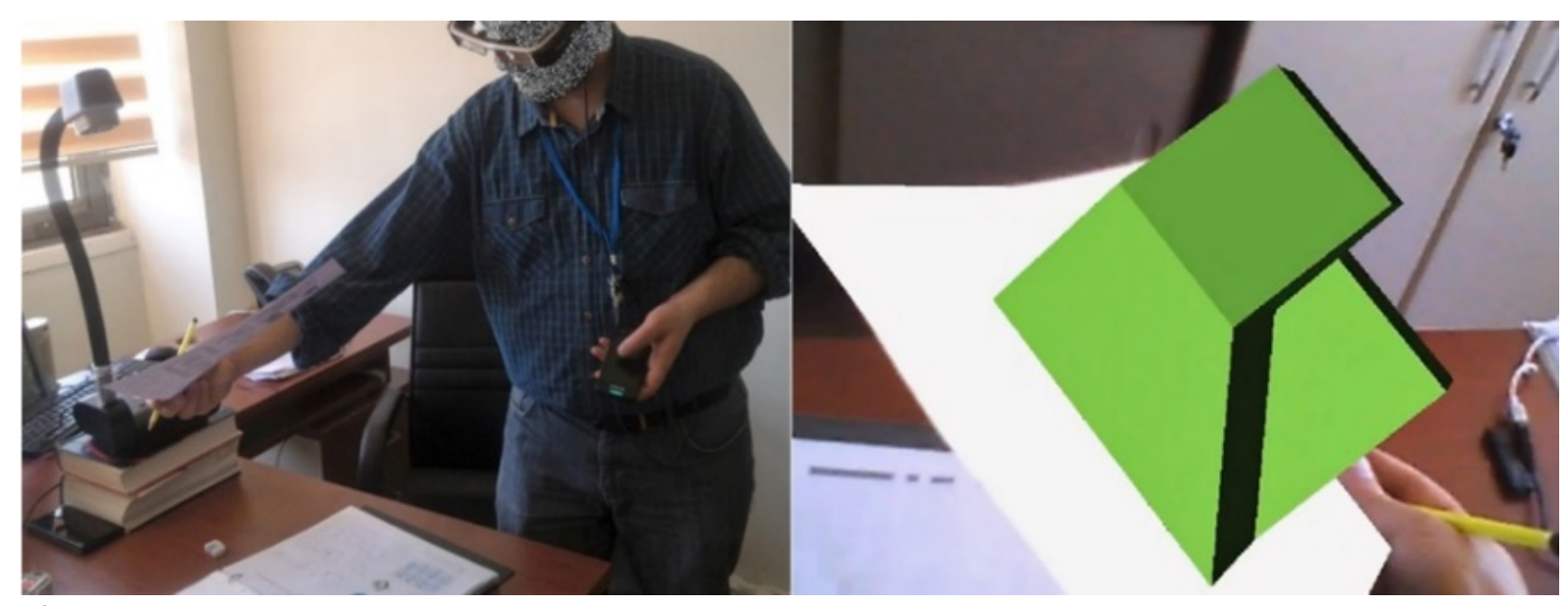

Figure 9. Holding a separate target page when examining a virtual object

regards to the directions of virtual objects or other technical issues. Therefore, with these revisions, the key elements of the AR interface were finalized.

\section{Booklets}

The SPATIAL-AR toolkit developed in this study included booklets since the AR interface was programmed as requiring target images to visualize virtual objects. The first version was designed as a single booklet containing both spatial tasks and related target images. In the focus group study, some issues related to the booklet's portability were raised. For example, whilst using the VR environment, one participant tried to hold the booklet in his hand since he could not see exact sides views of an object by traversing around the target image. However, this was an inefficient way to examine the object and write down notes on the task at the same time, since both the task and target images were contained in the same booklet. Therefore, the target image for the task was cut out from the booklet and the participant asked to hold the target image page separately. For instance, this was noted on observation notes as following:
"Bilge (pseudonym) could not understand one of the virtual objects in a task while working with smart glasses. He travelled around target image in order to see every angle of object. However, he could not see exact sides view of the object. Therefore, he tried to hold booklet but it was not efficient way for examining object and writing down notes on task at the same time since task and target images were on same booklet. Thus, target image for this task was cut from booklet and it was asked him to hold this page of target image separately (see Figure 9) (Observation notes about Bilge's works)".

Considering this issue as a solution process, it was conjectured that the booklet could be prepared separated into two parts, with a booklet of spatial tasks and a booklet of qr-codes, in order to provide ease of portability for booklets in the AR learning environment. That way, participants would be able to examine objects easier than using the draft design student's booklet, and the AR learning environment could become an environment which offers increased opportunities to students with more natural aspects of interaction and mobility (see Figure 10). 


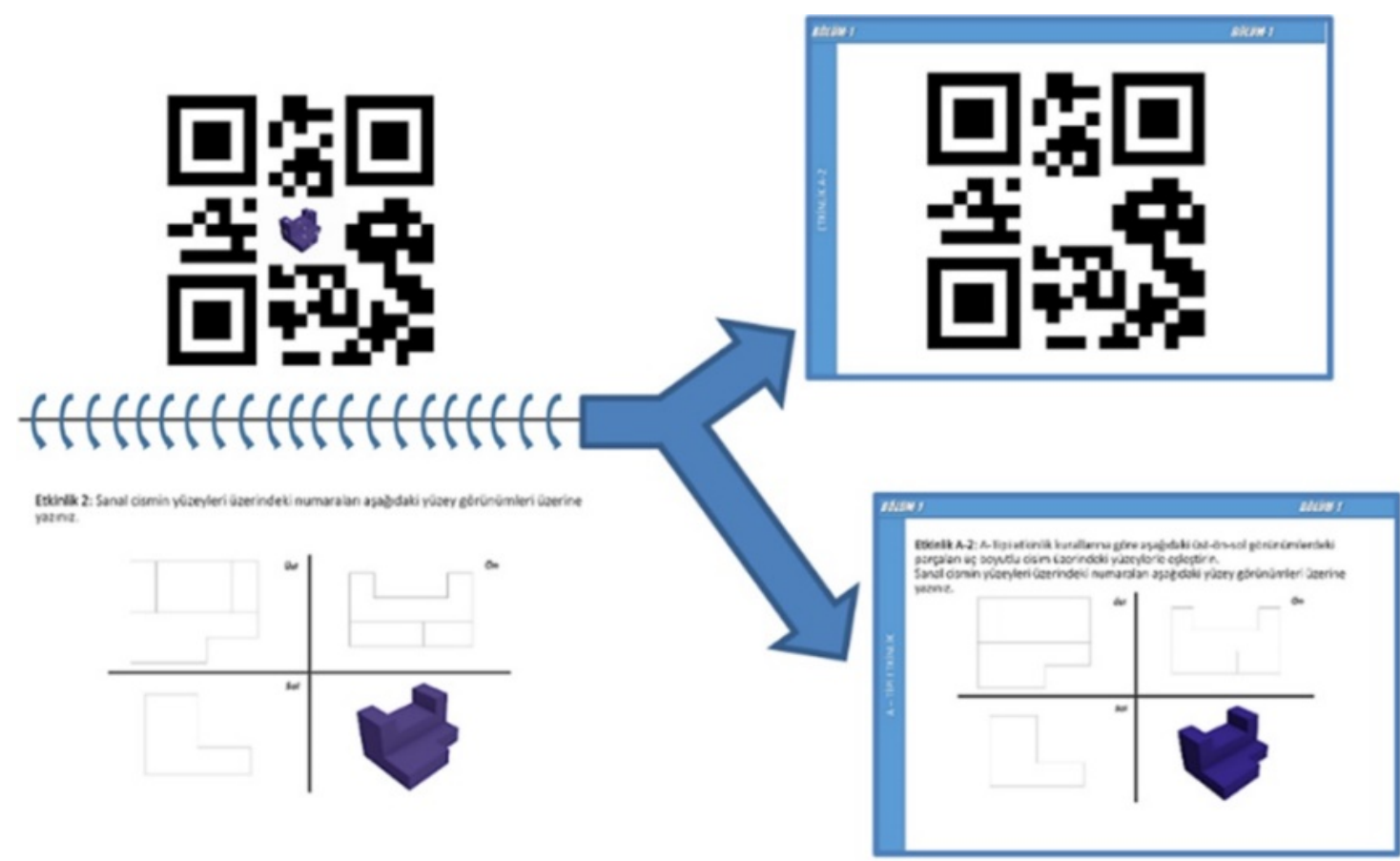

Figure 10. Revisions in design of booklets

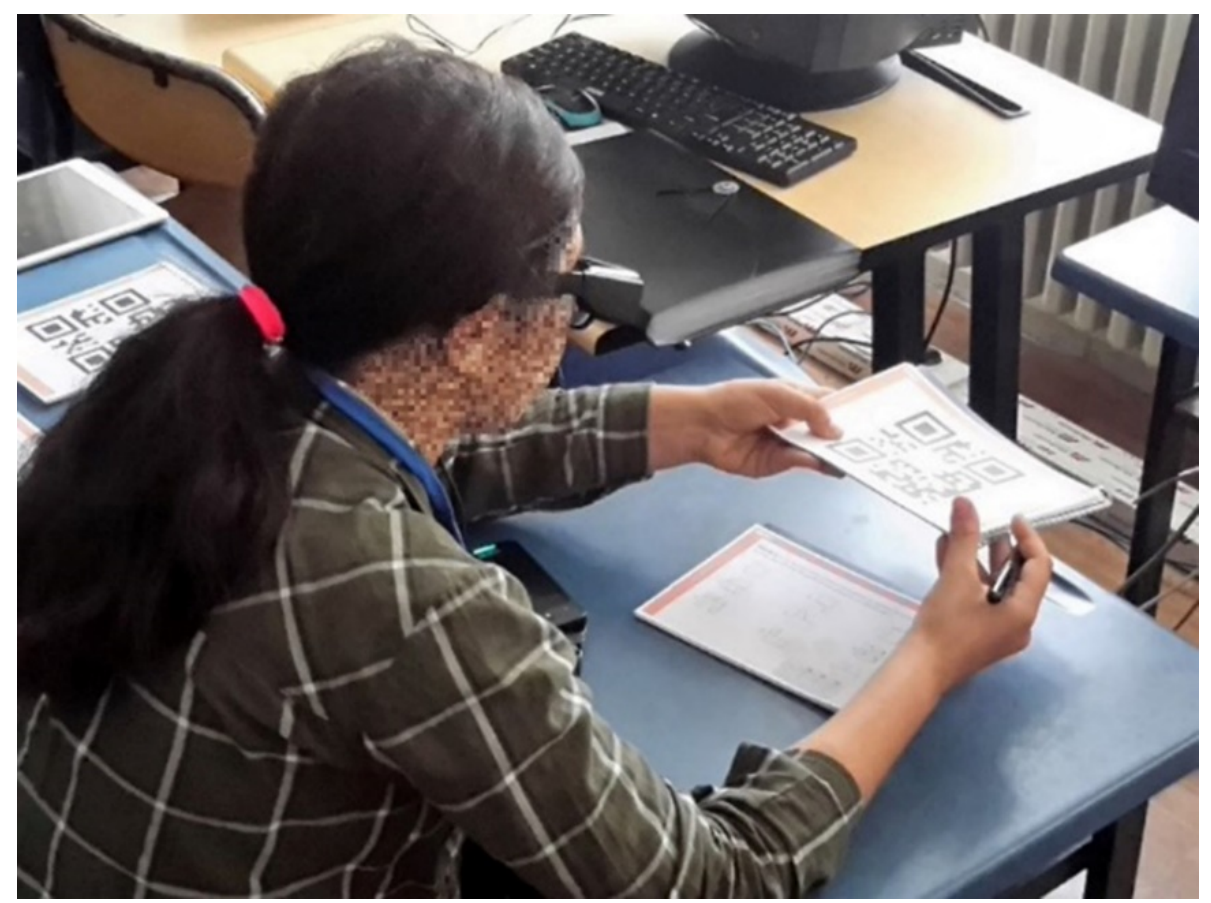

Figure 11. Meva moving and turning booklet freely

In accordance with these design changes, two new booklet types were designed and included in the second SPATIAL-AR prototype toolkit in order to serve as instructional tools of the walkthrough study. The findings of the first iteration directed the redesign of the booklets to be of a more coherent manner with the use of multiple booklets.

Findings from the walkthrough study revealed that the conjectures about mobility with this multiple booklet design completely fulfilled its design purpose (see Figure 11). In other words, as shown in the observation notes, no issues were raised about the design of the booklets in terms of their mobility and usability during the walkthrough study. 


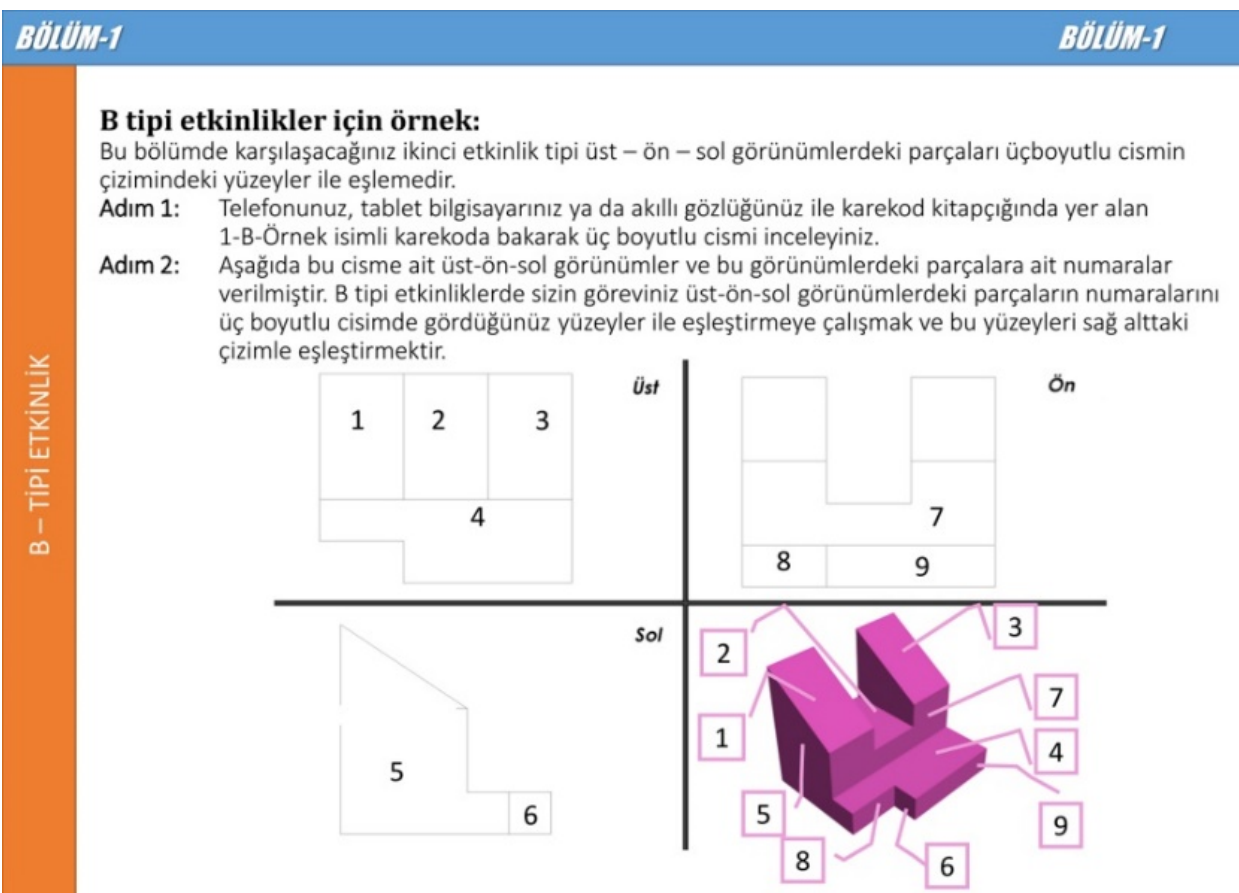

Figure 12. Example task about 3rd characteristic of the first category of the GISAR

However, it was observed that some of the students did not pay attention to the task descriptions during the instruction. Due to this issue, these students made errors with some of the tasks. The issue of disregarding task descriptions was queried in the retrospective interview session, with Meva and Elif stating the following;

\section{"I paid attention, but read only bold statements." [Meva, retrospective interview] \\ "I did not read the writing until...something went wrong...had some difficulties." [Elif, retrospective interview]}

In order to find a solution to this issue, some visual clues about task descriptions with clearer instructions were planned to be presented as a sample task for each task type, together with an introductory page for spatial tasks for each category of the GISAR (see Figure 12).

\section{Tasks}

According to the participants' comments and feedback, some virtual objects and spatial tasks were excluded from the first prototype SPATIAL-AR toolkit in order to strengthen the relevancy of the spatial tasks to the middle school mathematics curriculum and the consistency of these tasks to the GISAR. The second prototype of the SPATIAL-AR toolkit was designed and developed in order to serve as an instructional tool in the second iteration, the walkthrough study. Hence, the second prototype of the SPATIAL-AR toolkit was designed to include the remaining spatial tasks in accordance with the GISAR. During the walkthrough and the micro-evaluation study, observation notes revealed that the spatial tasks and virtual objects had been correctly prepared for the middle school mathematics curriculum, since the participants of the second and third iterations were not confused with any of the virtual objects or spatial tasks. They were able to examine the spatial tasks efficiently and adapted to the logic of the AR technology easily through these tasks as conjectured. Therefore, the tasks had been prepared in accordance with the characteristics of the GISAR and showed practical applicability in terms of the level of student understanding.

The focus group and walkthrough studies were the first occasion that the participants had used a tablet computer for this purpose, as well as using Smartglasses. Even so, observation notes and participant 


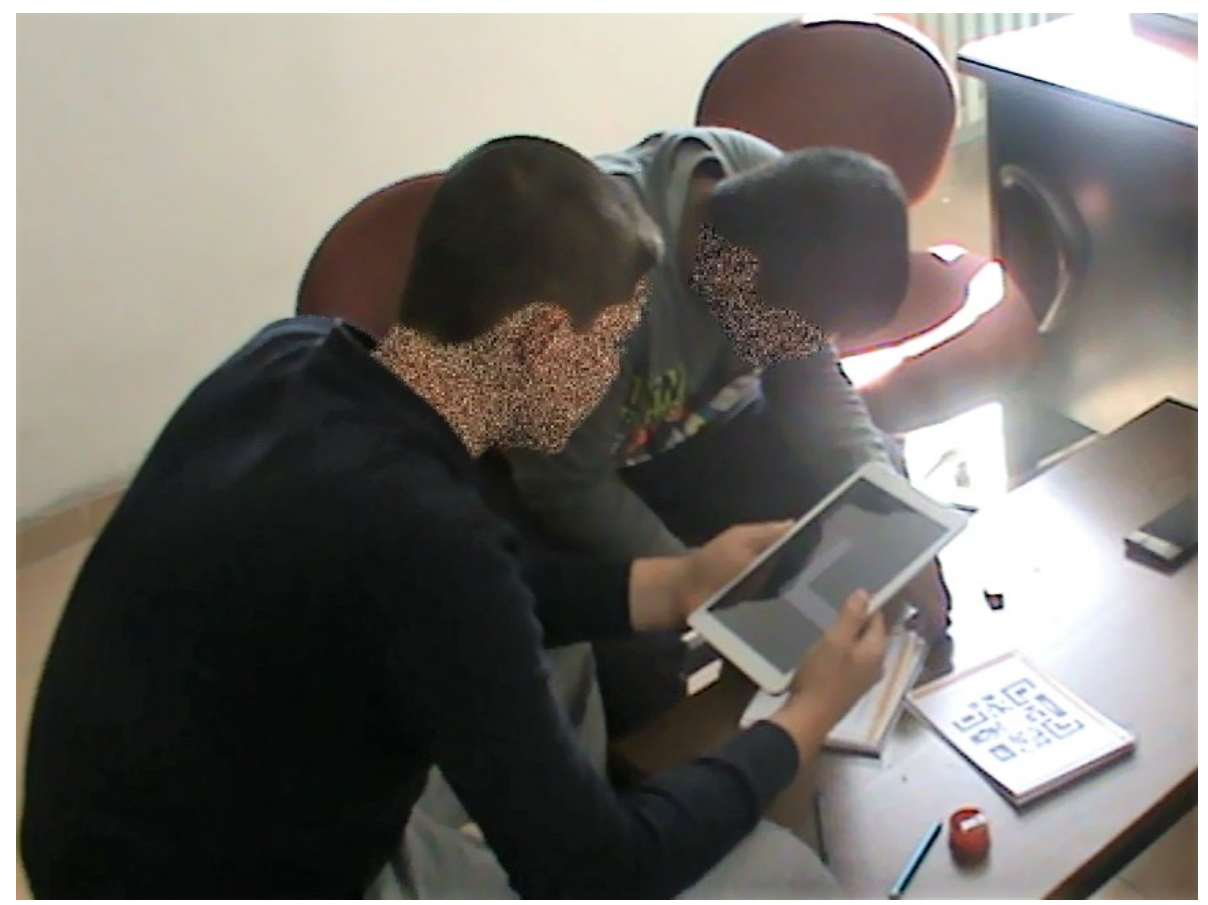

Figure 13. Investigating a virtual object for counting tasks

comments from the first iteration in the task-based interview sessions revealed that they easily adapted to the logic of AR technology when working on the spatial tasks of surfaces and vertices, and had not noticed which devices they had used, tablets or Smartglasses. For example;

\section{"One gets used to augmented reality after a while... Now, I don't feel that I'm dealing with a different technology." [task-based interview]}

It was observed that participants in the walkthrough study also easily adapted to the AR learning environment, even though this study was their first experience using AR within an educational setting. Furthermore, the spatial tasks based on the second category of the GISAR were also helpful in their becoming familiar with the usage of the AR interface, since it was observed that the participants looked at and examined every possible point of view for the virtual objects in order to find bricks that touched with each other, similar to the tasks related in the first category (see Figure 13).

The spatial tasks in the third and fourth categories of the GISAR were about connecting and relating three dimensional object and its two dimensional views from different angles. Therefore, these tasks were designed to require students to perform their spatial ability. It was seen that the participants worked fluently with these tasks and were able to make the transition of spatial information from threedimensional virtual objects to two-dimensional views. Therefore, it was understood that these tasks provided students with the opportunity to put into practice their spatial abilities as well as to recognize spatial relations. With these revisions about all design principles, the mobile AR interface and booklets were redesigned. The second prototype of SPATIAL-AR toolkit was designed and developed in order to serve as instructional tool at the second iteration which was the walkthrough study. Hence, the second prototype of SPATIAL-AR toolkit was designed including the remaining spatial tasks accordance with the GISAR.

In the preliminary research, some design principles for key features of an AR interface and AR learning environment were determined, as well as spatial contents for the GISAR. Due to the nature of the EDR, these initial design principles and GISAR were revised and refined throughout the iterations of the study. The reasons for these revisions and the practical usability of these design principles and the GISAR have been explained in detail; and in accordance with these revisions, reshaping stages of the SPATIAL-AR toolkit throughout the prototyping have also been explained. Lastly, the final design 


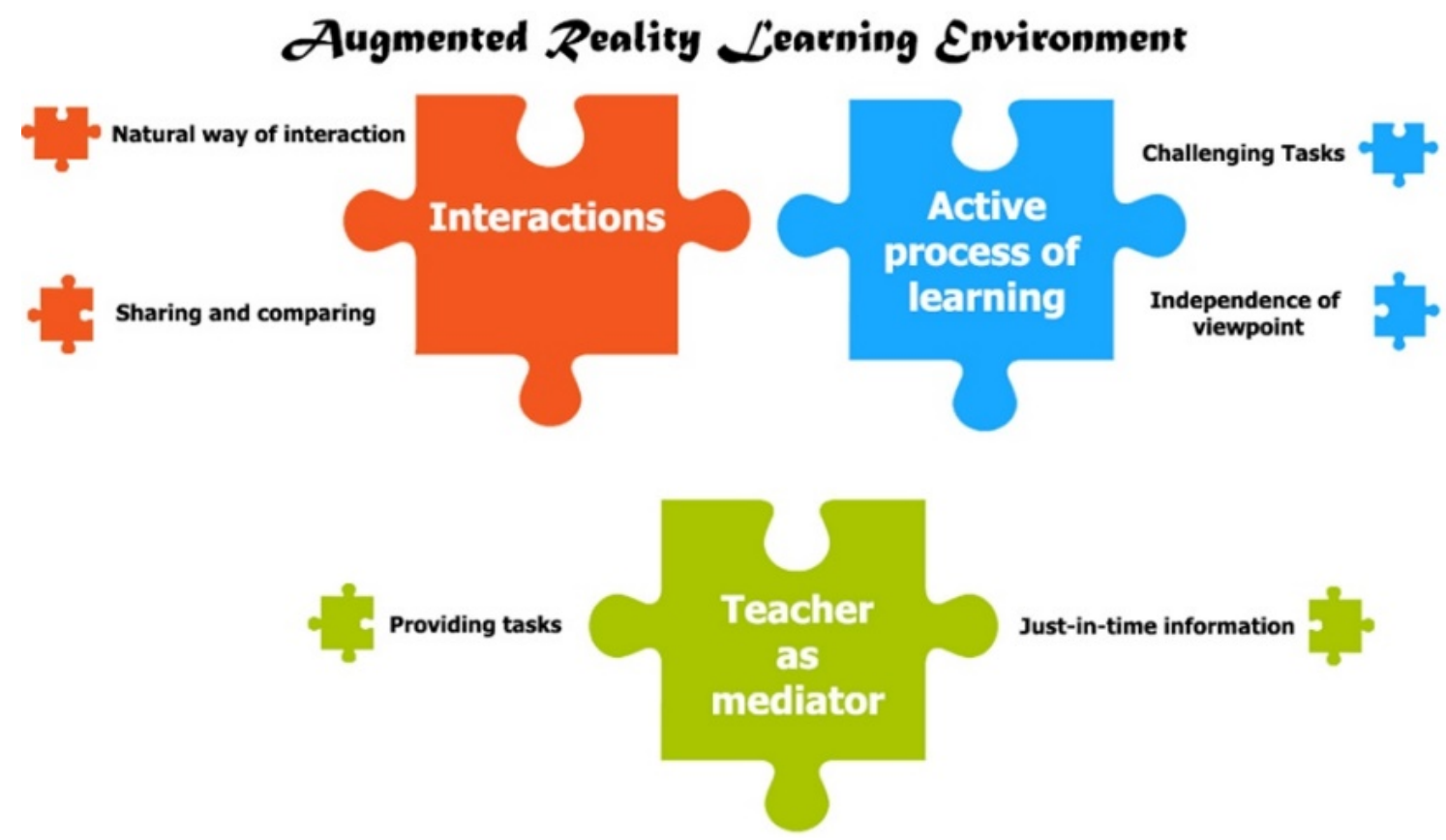

Figure 14. Characteristics of design principles for AR learning environment

principles were formed, and the SPATIAL-AR toolkit was revised and redesigned with regard to these principles.

\section{DISCUSSION}

Iterative cycles to design, formatively evaluate and revise the SPATIAL-AR toolkit prototypes throughout the study were handled based on their relevance to the intended middle school mathematics curriculum, consistency within the design, and practicality of its usage by students. This study led to the final set of design principles and the GISAR. Moreover, prototypes for intervention reached consistency in terms of design at the final iteration. The final prototype of the SPATIAL-AR toolkit for intervention, which was designed and developed in order to improve students' spatial ability, has shown some signs of practicality and usability with middle school students within an AR learning environment through the following design characteristics.

In light of the results, the AR learning environment design principles, which were reshaped in terms of learning opportunities in the learning environment, can be explained as three main characteristics (see Figure 14). First, the AR learning environment should provide opportunities to students for multi-user interaction through natural means of interaction with virtual objects, and explaining their findings by talking to each other or describing a virtual object by pointing and using their own terminology. These opportunities are along the same lines with the features of learning environments that support face-toface interaction (Lai, 2011), as well as the contributions of AR technology to learning environments (Matcha \& Rambli, 2011). Moreover, students should engage in an active process of learning with challenging tasks and being able to choose their own point of view to examine virtual objects within an AR learning environment, as stated by Szalavári et al. (1998), and Smith and MacGregor (1992). Furthermore, an AR interface should provide certain important elements in order to help teachers enhance collaborative works with students within the learning environment. Thus, according to Smith and MacGregor (1992), teachers become designers of intellectual learning experiences for students and take on the role of mediators in the AR learning environment.

Second, the key characteristics for a mobile AR interface, which were revised related to the technical aspects of the SPATIAL-AR prototype, were initially defined as virtuality for objects and augmentation of environment. These are "sine qua non" for all AR interfaces, since these characteristics differentiate AR environments from virtual reality (VR) environments. Moreover, according to the findings of the 


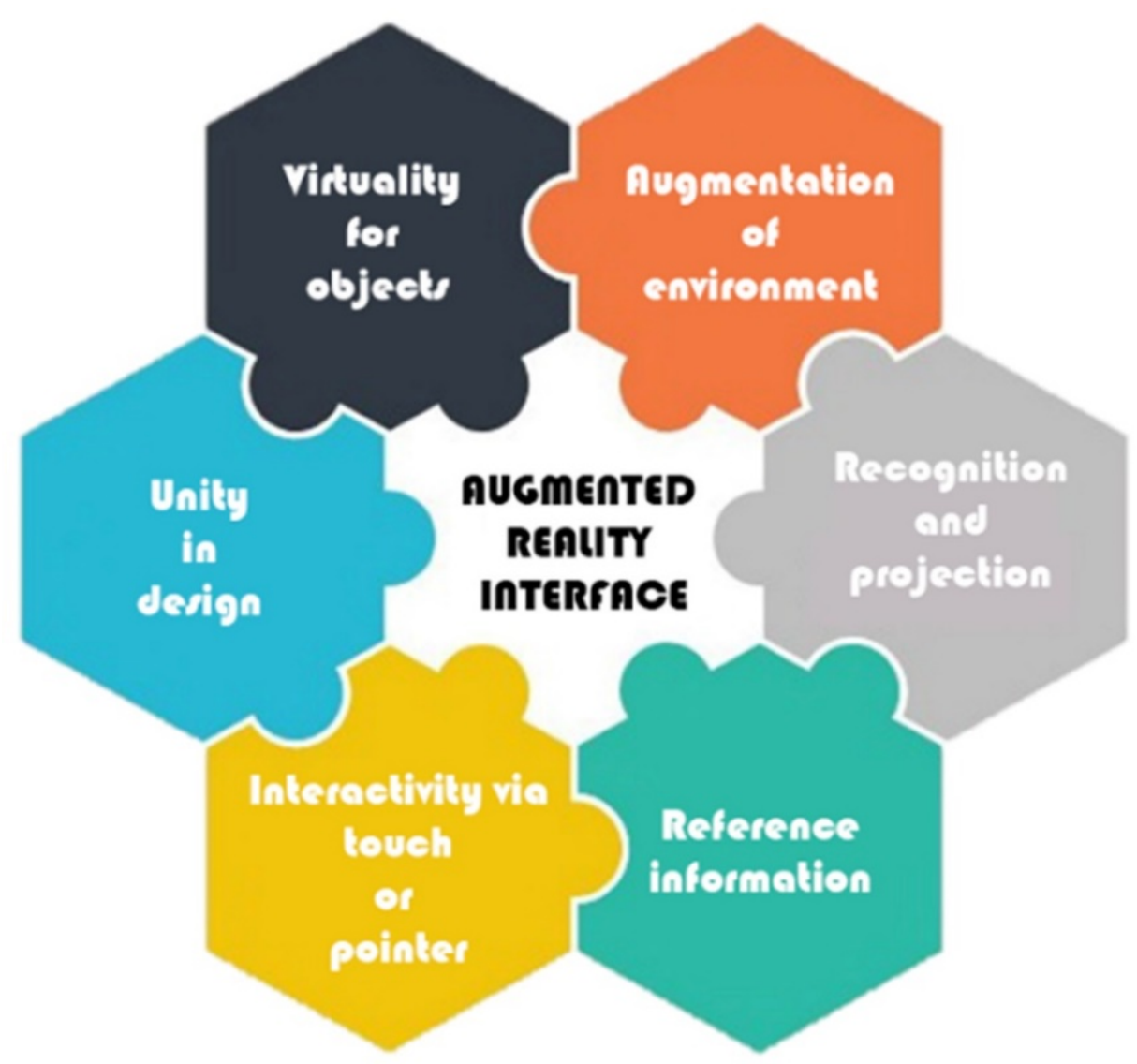

Figure 15. Design principles for key elements of a mobile AR interface

current study's phases, four new characteristics were added and validated for the design principles list of key elements of a mobile AR interface designed specifically for improving the spatial ability of middle school students (see Figure 15).

One of these characteristics is "recognition and projection," which refers to high-level discrimination in target images as recognizable target images, and object locations as relocating all virtual objects at a slightly higher position above the base layer in order to use the AR interface without object recognition issues being experienced by users. Other characteristics are about providing "reference information" to support teachers with AR-based just-in-time information feedback or with task clues for students, an "interactivity" feature to support the sharing and comparison of AR learning environment characteristics, and "unity in design" to maintain the AR interface in line with multiple spatial task categories. These characteristics are in line with studies by Azuma (1997), Hedley (2003), Kaufmann (2004), and Szalavári et al. (1998), who stated that the main purpose of AR is to enhance reality with virtuality, and to enable users to experience virtual elements as if they existed in the real-world environment.

In the current study, a target-based AR system was developed, and it was seen that multiple booklets provided a more functional learning environment for students. This meant that designing multiple booklets separately in terms of target images and tasks, as opposed to one single combined booklet, enhanced their portability and thereby afforded students increased opportunities for active learning as they were better able to achieve physical interaction by moving, holding or turning around the booklets (Sugimoto et al., 2004).

The findings of the current study guided the design of the booklets with certain characteristics as design principles for the AR booklets (see Figure 16). These principles were that AR booklets should provide visual cues for the identification of task types, present some introductory pages as well as task samples, 


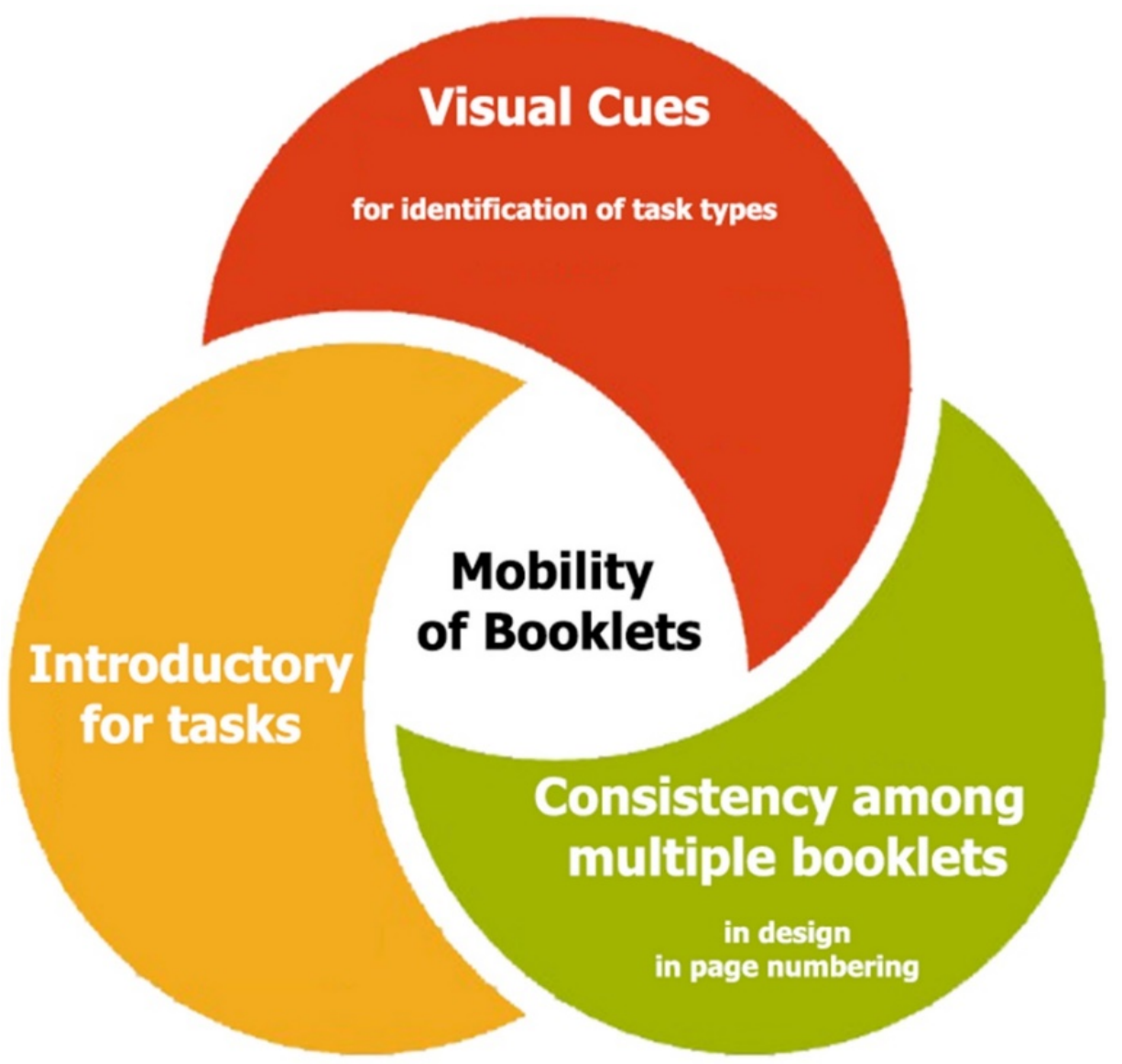

Figure 16. Final design principles for booklets

Table 2. The four-parted guides for improving spatial ability in an augmented reality environment

\begin{tabular}{ll}
\hline Parts & Spatial Contents \\
\hline Part 1: Surfaces \& Vertices & $\begin{array}{l}\text { Identification of surfaces on orthographic views } \\
\text { Identification of surfaces on perspective views } \\
\end{array}$ \\
\hline Identification of vertices on both orthographic and perspective views \\
\hline Part 2: Counting & Counting the number of components in touch with given component of a virtual object \\
\hline Part 3: Matching Correct Views & $\begin{array}{l}\text { Determining side views from organized orthographic views } \\
\text { Determining side views from disorganized orthographic views }\end{array}$ \\
\hline Part 4: The Second Dimension - & Sketching missing orthographic view \\
Sketches & Sketching all orthographic views from three directions \\
\hline
\end{tabular}

and to support consistency of design and page numbering among booklets. Therefore, the students could discriminate and determine related tasks and target images through simple visual information, without unnecessary distraction.

In the preliminary research phase, some models for training spatial ability and characteristics about contents of tasks for improving spatial ability of students which are suitable to AR were determined. The model of spatial operational capacity (Sack \& van Niekerk, 2009; Sack, 2013), Training of Spatial Ability (Martín-Gutiérrez et al., 2010) and spatial contents proposed by Wiesen (2015) consisted of a base for characteristics of spatial tasks. In this research, the characteristics of spatial contents were considered while designing spatial tasks, and revisited to be suitable for middle school students, seventh grade mathematics curriculum of Turkey and mobile AR systems. The revisions and additions of characteristics were explained in the previous sections of findings, in detail. According to findings of the study, the final GISAR included four sequential levels (Table 2). The GISAR was shaped to inform readers about sequential process of spatial tasks and their ingredient in terms of spatial contents as implemented in the whole study. 
This table also summarizes the spatial contents in different task types. The first two levels aimed to make students adapt and understand the AR technology by performing spatial tasks. Moreover, these two levels also aimed to make students think about some spatial strategies and perform them into tasks. The last two levels of the GISAR could be also named as analysis and synthesis levels since the spatial tasks of these levels required to understand spatial relationships between multiple objects, analyze relationships between two-dimensional spatial information with three dimensional one, and synthesis spatial information for two dimensional and three dimensional relations. Thus, these two levels could also provide opportunity for understanding students' spatial ability. Furthermore, students used some strategies to accomplish spatial tasks throughout the intervention. Therefore, the spatial tasks, in the same line with the GISAR, could also provide some opportunities for students to find and use relevant spatial strategies for spatial tasks. Within perspective of the GISAR, the GISAR only informs about spatial contents of tasks, but while implementing these series of spatial tasks in an AR learning environment, one could consider the characteristics of the final design principles for AR learning environment (see Figure 14).

\section{CONCLUSION AND SUGGESTIONS}

The design characteristics explained in the study were not intended to specify precise descriptions for the design and development of a mobile AR interface to foster spatial ability. Instead, they show a means of using a mobile AR interface to provide learning opportunities for improving students' spatial ability and to help teachers implement such learning opportunities within the classroom. In other words, teachers could be provided with this new tool to visualize mathematical concepts, and students could be supported with new learning material through application of the SPATIAL-AR for mobile devices. Moreover, curriculum developers and researchers may benefit from the design principles identified for the AR learning environment in order to achieve properly adjusted learning environments that are suitable for AR, design principles for booklets in order to make textbooks appropriate for AR tasks, and the GISAR in order to design spatial tasks for AR-based learning. Furthermore, these design principles could provide the basic developmental and implementation characteristics for making AR technology applicable and usable in learning, especially for spatial ability development in middle school students. Preservice teachers could be trained to learn and apply simple coding steps in order to develop their coding skills. Hence, they could possess the basic skills to develop an AR interface for learning situations in order to implement in their future classrooms. Furthermore, the set of spatial tasks of the SPATIALAR toolkit provides the essence for spatial contents in the study. These tasks were designed along with the GISAR which comes from methodologies about fostering spatial ability in the literature and constitute a model for spatial ability specifically in an AR learning environment. The GISAR was formed with four sequential levels. The first two levels help student understand and adapt logic of AR technology with its usage with tasks. Moreover, these levels provide students opportunities to comprehend spatial relationships within and between virtual objects. The other remaining levels which are matching, and sketching side views requires students analyze and synthesize three dimensional spatial information to two dimensional one from these spatial relationships. Therefore, teachers could use this model as base for their activities both to provide opportunities for fostering spatial ability and to determine current level of spatial ability of their students. In other words, the MISAR provides opportunities for teachers designing spatial tasks to train spatial ability as well as measure it.

Because the AR technology is relatively new technology and devices like smart glasses are expansive, the results of this study are limited to a small number of participants. Therefore, findings of this study are limited to similar environment and students have similar characteristics. Moreover, the spatial tasks and the GISAR developed throughout this study can be applicable to similar environment in such possessed similar technological potential. Moreover, it had been difficult to code new virtual threedimensional objects in runtime for the coded AR interface with existed source codes and scripts since the researcher, who was also real developer and coder of this toolkit, had a degree form mathematics education. Therefore, students were limited to explore pre-designed virtual objects and they cannot create new virtual objects. This factor stands technological limitations of this study. Apart from 
designing and developing processes of an AR interface, implementation of such AR interface in a learning environment was seem very easy and practical. In fact, both seventh graders and mathematics education experts were accustomed the AR learning environment at a time. The novelty of this environment vanished on the first day of implementation and they were able to use the SPATIAL-AR toolkit without dealing with neither technical nor practical issues. On the contrary to other technologybased systems, since inputs and control of AR interface can be done with natural and physical ways of interactions like moving body parts, gesturing, touching, tilting, moving and others, students and experts were not distracted with indirect way of controls like with mouse or keyboards. Therefore, they could use the mobile AR interface like they were using a concrete material, and so the mobile AR interface was not novel for them after a while. As stated at the beginning of this paragraph, apart from designing an AR interface, other things are practical. The AR interface of this study was developed nearly from scratch by writing and compiling some C\# scripts as well as helps of some software development kits. However, teachers might not design AR interface for their lessons if they have not enough practice for coding a program. Therefore, studies for AR technology for educational settings should provide clear directions or characteristics for anyone who want to design an AR learning environment for own lessons and students. Moreover, future studies should be also conducted to provide comprehensive frameworks and design procedures for implementation of AR environment for different educational practices in order to provide valuable and numerous design products which can serve valuable AR based learning materials for education. Hence, teachers can use such AR interfaces which are validated in terms of their practical and effective implementations, as a teaching tool along with tablets or even smart phones. Furthermore, researchers should provide more dynamic and interactive AR interfaces like GeoGebra and Cabri 3D as well as design principles such interfaces. Hence, dynamic geometry software would have augmented features so that students would have opportunities for direct interactions with virtual three dimensional objects in dynamic geometry environments without experiencing negative effects of cognitive filter issue which was also focus of this study.

\section{ABBREVIATIONS}

$\begin{array}{ll}\text { AR } & \text { Augmented Reality } \\ \text { SPATIAL-AR } & \text { Spatial Augmented Reality } \\ \text { EDR } & \text { Education Design Research } \\ \text { GISAR } & \text { Guides for Improving Spatial Ability with AR } \\ \text { VR } & \text { Virtual Reality }\end{array}$

Author contributions: This research is a revision from first author's doctoral dissertation with supervision of the second author. The authors read and approved the final manuscript.

Funding: The authors received no financial support for the research and/or authorship of this article.

Acknowledgements: This article is a revision of first author's doctoral dissertation from Middle East Technical University, Turkey. We acknowledge and thank the contributions from members of thesis committee who shared their perspectives, thereby enabling this research to be completed.

Declaration of interest: Authors declare no competing interest.

Ethics declaration: All procedures performed in studies involving human participants were in accordance with the ethical standards of Human Studies Commission at Applied Ethics Research Center of Middle East Technical University with protocol number 2016-EGT-019. Informed consent was obtained from all individual participants included in the study.

Data availability: The data that support the findings of this study are not publicly available due to containing information that could compromise the privacy of research participants, since most of the data were gathered through video recordings.

Authors' information: Bilal Ozcakir, Ph.D is an assistant professor of Mathematics Education in Alanya Alaaddin Keykubat University. His research interests include middle school mathematics education, technology integration in education and usage of novel technologies for education. Erdinc Cakiroglu, Ph.D is a professor of Mathematics Education in Middle East Technical University. His research interests include mathematics teacher education, learning of number concepts and operations, and curriculum design. 


\section{REFERENCES}

Alcañiz, M., Contero, M., Pérez-López, D. C., \& Ortega, M. (2010). Augmented reality technology for education. In S. Soomro (Ed.), New achievements in technology education and development (pp. 247-256). InTech. https://doi.org/10.5772/9228

Azuma, R. T. (1997). A survey of augmented reality. Presence-Teleoperators and Virtual Environments, 6(4), 355-385. https://doi.org/10.1162/pres.1997.6.4.355

Battista, M. T. (1990). Spatial visualization and gender differences in high school geometry. Journal for Research in Mathematics Education, 21(1), 47-60. https://doi.org/10.5951/jresematheduc.21.1.0047

Battista, M. T. (1994). On Greeno's environmental/model view of conceptual domains: A spatial/geometric perspective. Journal for Research in Mathematics Education, 25(1), 86-99. https://doi.org/10.5951/jresematheduc.25.1.0086

Battista, M. T. (2007). The Development of Geometric and Spatial Thinking. In F. K. Lester (Ed.), Second handbook of research on mathematics teaching and learning. Information Age Publishing.

Billinghurst, M., \& Kato, H. (2002). Collaborative augmented reality. Communications of the ACM, 45(7), 64-70. https://doi.org/10.1145/514236.514265

Chen, Y. (2019). Effect of Mobile Augmented Reality on Learning Performance, Motivation, and Math Anxiety in a Math Course. Journal of Educational Computing Research, 57(7), 1695-1722. https://doi.org/10.1177/0735633119854036

Creswell, J. W., \& Poth, C. N. (2016). Qualitative inquiry and research design: Choosing among five approaches. Sage publications.

Demitriadou, E., Stavroulia, K.-E., \& Lanitis, A. (2020). Comparative evaluation of virtual and augmented reality for teaching mathematics in primary education. Education and Information Technologies, 25(1), 381-401. https://doi.org/10.1007/s10639019-09973-5

Dünser, A., Steinbügl, K., Kaufmann, H., \& Glück, J. (2006). Virtual and augmented reality as spatial ability training tools. Proceedings of the 7th ACM SIGCHI New Zealand chapter's international conference on Computer-human interaction: design centered HCI, New York, NY. https://doi.org/10.1145/1152760.1152776

Elsayed, S. A., \& Al-Najrani, H. I. (2021). Effectiveness of the augmented reality on improving the visual thinking in mathematics and academic motivation for middle school students. Eurasia Journal of Mathematics, Science and Technology Education, 17(8), em1991. https://doi.org/10.29333/ejmste/11069

Fennema, E., \& Sherman, J. (1977). Sex-related differences in mathematics achievement, spatial visualization and affective factors. American Educational Journal, 14(1), 51-71. https://doi.org/10.3102/00028312014001051

Flores-Bascuñana, M., Diago, P. D., Villena-Taranilla, R., \& Yáñez, D. F. (2020). On augmented reality for the learning of 3Dgeometric contents: A preliminary exploratory study with 6-grade primary students. Education Sciences, 10(1), 4. https://doi.org/10.3390/educsci10010004

Frank, J. A., \& Kapila, V. (2017). Mixed-reality learning environments: Integrating mobile interfaces with laboratory test-beds. Computers $\mathcal{E}$ Education, 110, 88-104. https://doi.org/10.1016/j.compedu.2017.02.009

Guay, R. B. (1977). Purdue spatial visualization test - Visualization of rotations. Purdue Research Foundation.

Hedley, N. (2003). Empirical evidence for advanced geographic visualization interface use. International Cartographic Congress: Cartographic Renaissance, Durban, South Africa.

Kaufmann, H. (2004). Geometry education with augmented reality [Doctoral dissertation, Vienna University of Technology]. Vienna, Austria. https://doi.org/10.1145/1242073.1242086

Kaufmann, H., \& Schmalstieg, D. (2002). Mathematics and geometry education with collaborative augmented reality. ACM SIGGRAPH 2002 conference abstracts and applications, San Antonio, Texas. https://doi.org/10.1145/1242073.1242086

Lai, E. R. (2011). Collaboration: A literature review. http://images.pearsonassessments.com/images/tmrs/collaboration-review.pdf

Linn, M. C., \& Petersen, A. C. (1985). Emergence and characterisation of gender differences in spatial abilities: A meta-analysis. Child Development, 56, 1479-1498. https://doi.org/10.2307/1130467

Lohman, D. F. (1993). Spatial Ability and G First Spearman Seminar, Iowa City, Iowa.

Maier, P. H. (1996). Spatial geometry and spatial ability-How to make solid geometry solid. The Annual Conference of Didactics of Mathematics, Munich, Germany.

Maiti, A., \& Tripathy, B. (2012). Different platforms for remote laboratories in mobile devices. International Journal of Modern Education Computer Science, 4(5), 38-45. https://doi.org/10.5815/ijmecs.2012.05.06

Martín-Gutiérrez, J., Saorín, J. L., Contero, M., Alcañiz, M., Pérez-López, D. C., \& Ortega, M. (2010). Design and validation of an augmented book for spatial abilities development in engineering students. Computers Graphics, 34(1), 77-91. https://doi.org/10.1016/j.cag.2009.11.003

Matcha, W., \& Rambli, D. R. A. (2011). Preliminary investigation on the use of augmented reality in collaborative learning. International Conference on Informatics Engineering and Information Science, Berlin, Heidelberg. https://doi.org/10.1007/978-3642-25483-3_15

MoNE. (2013). Ortaokul matematik dersi (5-8. sinıflar) öğretim programı [Middle school mathematics course (5th-8th grades) curriculum]. Board of Education and Discipline.

NCTM. (1989). Curriculum and evaluation standards for school mathematics. National Council of Teachers of Mathematics. 
Nieveen, N., \& Folmer, E. (2013). Formative evaluation in educational design research. In J. Van den Akker, K. Gravemeijer, S. McKenney, \& N. Nieveen (Eds.), Educational design research (pp. 152-169). Routledge.

Olkun, S. (2003). Making connections: Improving spatial abilities with engineering drawing activities. International Journal of Mathematics Teaching and Learning, 3(1), 1-10. https://doi.org/10.1501/0003624

Pellegrino, J. W., \& Kail, R. (1982). Process analices of spatial aptitude. In R. J. Sternberg (Ed.), Advances in the psychology of human intelligence (Vol. 1, pp. 311-365). Lawrance Erlbaum Associates.

Plomp, T. (2013). Educational design research: An introduction. In N. Nieveen \& T. Plomp (Eds.), An introduction to educational design research (pp. 11-50). SLO.

Rafi, A., Samsudin, K. A., \& Said, C. S. (2008). Training in spatial visualization: The effects of training method and gender. Educational Technology \& Society, 11(3), 127-140.

Sack, J. J. (2013). Development of a top-view numeric coding teaching-learning trajectory within an elementary grades 3D visualization design research project. The Journal of Mathematical Behavior, 32(2), 183-196. https://doi.org/10.1016/j.jmathb.2013.02.006

Sack, J., \& van Niekerk, R. (2009). Developing the spatial operational capacity of young children using wooden cubes and dynamic simulation software. In T. Craine \& R. Rubenstein (Eds.), Understanding geometry for a changing world: Seventy-first yearbook (pp. 141-154). National Council of Teachers of Mathematics.

Shelton, B. E. (2003). How augmented reality helps students learn dynamic spatial relationships [Doctoral dissertation, University of Washington]. Seattle.

Shelton, B. E., \& Hedley, N. R. (2004). Exploring a cognitive basis for learning spatial relationships with augmented reality. Technology, Instruction, Cognition and Learning, 1(4), 323-357.

Sjölinder, M. (1998). Spatial cognition and environmental descriptions. Towards a framework for design and evaluation of navigation in electronic spaces.

Smith, B. L., \& MacGregor, J. T. (1992). What is collaborative learning? In A. S. Goodsell, M. R. Maher, \& V. Tinto (Eds.), Collaborative Learning: A Sourcebook for Higher Education (pp. 10-30). Syracuse University.

Stiles, J., \& Stern, C. (2001). Developmental change in spatial cognitive processing: Complexity effects and block construction performance in preschool children. Journal of Cognition and Development, 2(2), 157-187. https://doi.org/10.1207/S15327647JCD0202_3

Sugimoto, M., Hosoi, K., \& Hashizume, H. (2004). Caretta: a system for supporting face-to-face collaboration by integrating personal and shared spaces. Proceedings of the SIGCHI conference on Human Factors in Computing Systems, New York, NY. https://doi.org/10.1145/985692.985698

Sundberg, S. E. (1996). Effect of spatial training on spatial ability and mathematical achievement as compared to traditional geometry instruction [Doctoral dissertation, University of Missouri]. Kansas City.

Szalavári, Z., Schmalstieg, D., Fuhrmann, A., \& Gervautz, M. (1998). "Studierstube": An environment for collaboration in augmented reality. Virtual Reality, 3(1), 37-48. https://doi.org/10.1007/BF01409796

Tartre, L. A. (1990). Spatial orientation skill and mathematical problem solving. Journal for Research in Mathematics Education, 21(3), 216-229. https://doi.org/10.5951/jresematheduc.21.3.0216

Uygan, C., \& Kurtuluş, A. (2016). Effects of teaching activities via Google Sketchup and concrete models on spatial skills of preservice mathematics teachers. Turkish Journal of Computer and Mathematics Education, 7(3), 510-535. https://doi.org/10.16949/turkbilmat.273993

van Garderen, D. (2006). Spatial visualization, visual imagery, and mathematical problem solving of students with varying abilities. Journal of Learning Disabilities, 39(6), 496-506. https://doi.org/10.1177/00222194060390060201

Wiesen, J. (2015). Barron's mechanical aptitude and spatial relations test (3rd ed.). Barron's Educational Series. https://books.google.com.tr/books?id=KBzNoQEACAAJ

Wu, H.-K., Lee, S. W.-Y., Chang, H.-Y., \& Liang, J.-C. (2013). Current status, opportunities and challenges of augmented reality in education. Computers and Education, 62(3), 41-49. https://doi.org/10.1016/j.compedu.2012.10.024

Yakimanskaya, I. S. (1991). The development of spatial thinking in school children. In P. S. Wilson \& E. J. Davis (Eds.), Soviet studies in mathematics education (Vol. 5). National Council of Teachers of Mathematics. 